\title{
ahr2, But Not ahr1a or ahr1b, Is Required for Craniofacial and Fin Development and TCDD- dependent Cardiotoxicity in Zebrafish
}

\author{
Jaclyn P. Souder ${ }^{*, \dagger}$ and Daniel A. Gorelick ${ }^{*,+, 1}$
}

"Medical Scientist Training Program \& Department of Pharmacology and Toxicology, University of Alabama at Birmingham, Birmingham, Alabama, 35294; and ${ }^{\dagger}$ Department of Molecular and Cellular Biology, Center for Precision Environmental Health, Baylor College of Medicine, Houston, Texas, 77030

${ }^{1}$ To whom correspondence should be addressed. Fax: (713) 798-8181; E-mail: gorelick@bcm.edu.

\begin{abstract}
The aryl hydrocarbon receptor (AHR) is a ligand-activated transcription factor that binds environmental toxicants and regulates gene expression. AHR also regulates developmental processes, like craniofacial development and hematopoiesis, in the absence of environmental exposures. Zebrafish have 3 paralogs of AHR: ahr1a, ahr1b, and ahr2. Adult zebrafish with mutations in ahr2 exhibited craniofacial and fin defects. However, the degree to which ahr1a and $a h r 1 b$ influence $a h r 2$ signaling and contribute to fin and craniofacial development are not known. We compared morphology of adult ahr2 mutants and ahr1a;ahr1b single and double mutant zebrafish. We found that ahr1a;ahr1b single and double mutants were morphologically normal whereas ahr2 mutant zebrafish demonstrated fin and craniofacial malformations. At 5 days post fertilization, both ahr1a;ahr1b and ahr2 mutant larvae were normal, suggesting that adult phenotypes are due to defects in maturation or maintenance. Next, we analyzed the function of zebrafish AHRs activated by environmental ligands. The prototypical AHR ligand, 2,3,7,8-tetrachlorodibenzo-p-dioxin (TCDD), induces toxicity in humans and rodents via AHR and causes cardiotoxicity in zebrafish embryos. It has been shown that embryos with mutations in ahr2 are resistant to TCDD toxicity, yet it is unclear whether ahr1 receptors are required. Furthermore, though AHR was shown to interact with estrogen receptor alpha following TCDD treatment, it is not known whether this interaction is constitutive or context-dependent. To determine whether estrogen receptors are constitutive cofactors for AHR signaling, we used genetic and pharmacologic techniques to analyze TCDD-dependent toxicity in estrogen receptor and $a h r$ mutant embryos. We found that embryos with mutations in $a h r 1 a ; a h r 1 b$ or estrogen receptor genes are susceptible to TCDD toxicity whereas ahr2 mutant embryos are TCDD-resistant. Moreover, pharmacologic blockade of nuclear estrogen receptors failed to prevent TCDD toxicity. These findings suggest that ahr1 genes do not have overlapping functions with ahr2 in fin and craniofacial development or TCDD-dependent toxicity, and that estrogen receptors are not constitutive partners of ahr2.
\end{abstract}

Key words: dioxin; agents, aquatic toxicology; environmental toxicology, nonmammalian species; environmental toxicology, receptor; aryl hydrocarbon; gene expression/regulation, receptor; nuclear hormone; gene expression/regulation, endocrine; receptor; endocrine toxicology.

The aryl hydrocarbon receptor (AHR) is a ligand-activated transcription factor (Burbach et al., 1992). In the nucleus, AHR forms a heterodimer with aryl hydrocarbon receptor nuclear translocator (ARNT) (Reyes et al., 1992). The AHR-ARNT complex recruits transcription factors and binds xenobiotic response elements (XREs) in DNA to regulate gene transcription (Cuthill 
et al., 1989; Denison et al., 1988a,b; Fujisawa-Sehara et al., 1987 1988; Hapgood et al., 1989). Target genes of AHR include the cytochrome P450 family of genes (eg CYP1A), which are involved in the metabolism and clearance of toxic compounds (Burbach et al., 1992; Reyes et al., 1992).

The AHR ligand 2,3,7,8-tetrachlorodibenzo-p-dioxin (TCDD) is resistant to metabolism and is toxic (Flesch-Janys et al., 1995; Henry et al., 1997). Murine models deficient in AHR (Ahr-/-) are resistant to the effects of TCDD, confirming that AHR is required for TCDD-dependent toxicity (Bunger et al., 2003, 2008; Fernandez-Salguero et al., 1995, 1996). Aryl hydrocarbon receptor also binds endogenous ligands to regulate organismal development. Evidence from $\mathrm{Ahr}-/$ - mice demonstrated that AHR regulates organ development, including hematopoiesis, heart, and liver development (Bunger et al., 2003, 2008; FernandezSalguero et al., 1995; Gonzalez and Fernandez-Salguero, 1998; Singh et al., 2011; Thackaberry et al., 2003). However, the proteins and signaling pathways with which AHR interacts to regulate development are not completely understood. Understanding how AHR functions during development is essential to determine the role of AHR in cases of disrupted development, including congenital heart disease and blood/immune disorders.

To visualize the function of AHR during embryonic development, we turned to the zebrafish model system. Zebrafish produce externally fertilized embryos that are transparent, allowing rapid analysis of organ formation in live embryos. Aryl hydrocarbon receptor is conserved throughout the vertebrate lineage, including zebrafish (Hahn et al., 1997). Zebrafish embryos are sensitive to TCDD exposure, exhibiting severe pericardial edema (PCE), abnormal heart looping, circulation failure, disrupted erythropoiesis, and reduced jaw length (Belair et al., 2001; Henry et al., 1997; Teraoka et al., 2002). In contrast to mice, zebrafish have 3 paralogs of AHR: ahr1a, ahr1b, and ahr2 (Andreasen, Hahn, et al., 2002; Karchner et al., 2005; Tanguay et al., 1999). In this study, we sought to understand the contribution of each of the zebrafish Ah receptors to TCDD toxicity, fin development, and craniofacial development.

Zebrafish ahr2 is thought to be the primary functional homolog of the human AHR based on studies using recombinant Ahr2 protein in vitro and ahr2 mutant zebrafish. Ahr2 binds ligands like TCDD, forms a heterodimer with a zebrafish ARNT paralog (arnt2) on XRE DNA and induces expression of AHR target genes like CYP1A1 (Andreasen, Hahn, et al., 2002; Andreasen, Spitsbergen, et al., 2002; Garcia et al., 2018; Goodale et al., 2012; Prasch et al., 2003; Tanguay et al., 1999, 2000).

Of the zebrafish ahr genes, ahrla has the highest sequence similarity to human AHR. However, the function of $a h r 1 a$ is not clear. Although zebrafish Ahr1a protein was shown to bind Arnt $2 b$ at XRE DNA in vitro, this interaction was qualitatively weaker than the Ahr2/Arnt2b/XRE interaction (Andreasen, Hahn, et al., 2002; Andreasen, Spitsbergen, et al., 2002). Furthermore, Ahr1a was unable to activate XRE reporter activity in cultured cells (Andreasen, Hahn, et al., 2002; Andreasen, Spitsbergen, et al., 2002). Ligand binding assays demonstrated that Ahr1a lacks the ability to bind $\left[{ }^{3} \mathrm{H}\right] \mathrm{TCDD}$ (Andreasen, Hahn, et al., 2002). This suggests that Ahr1a may be a nonfunctional AHR paralog. Later studies using morpholino oligonucleotides to knockdown expression of ahrla in zebrafish embryos suggested that ahr1a mediates the response to pyrene, polyaromatic hydrocarbon (PAH), and leflunomide (Garner et al., 2013; Goodale et al., 2012; Incardona et al., 2006). In contrast, a study using TALEN-mediated mutation of ahrla demonstrated that Ahr1a was not required for CYP1A1 expression (Sugden et al., 2017). Thus, an endogenous role for ahr1a has not been elucidated.
In contrast to Ahr1a, zebrafish Ahr1b binds $\left[{ }^{3} \mathrm{H}\right] \mathrm{TCDD}$ and Arnt $2 \mathrm{~b}$ and induces XRE-dependent transcription in cultured cells (Karchner et al., 2005). The $\mathrm{EC}_{50}$ of TCDD for Ahr1bmediated XRE activation is 8-fold higher than for Ahr2 protein (Karchner et al., 2005). This suggests that Ahr1b may regulate toxic response to dioxins at higher concentrations, whereas Ahr2 regulates this response at lower concentrations. Morpholino studies suggest that Ahr1b is not required for the response to PAH-mediated toxicity in zebrafish embryos (Garner et al., 2013), but is required in part for leflunomideinduced CYP1A1 activity (Goodale et al., 2012). These results, combined with studies investigating ahrla function, suggest that activation of $\mathrm{Ah}$ receptors is ligand-dependent.

We now appreciate that morpholinos are prone to off-target effects (Blum et al., 2015; Gerety and Wilkinson, 2011; SchulteMerker and Stainier, 2014; Stainier et al., 2015). There is poor correlation between morpholino-induced and mutant phenotypes in zebrafish embryos (Kok et al., 2014). Thus, any observed ahr1a and $a h r 1 b$ morpholino phenotypes may not be specific to $a h r 1$ knockdown. In addition, genetic compensation could mask a phenotype in ahrla or ahr1b single mutants. Here, we generate and analyze single and double ahr1a and ahr1b mutant embryos.

Although ARNT is thought to be an obligate cofactor for AHR (Reyes et al., 1992), additional proteins are also recruited by AHR to mediate changes in gene transcription (Kumar and Perdew, 1999; Nguyen et al., 1999). Several instances of crosstalk between AHR and nuclear estrogen receptors alpha and beta (ER $\alpha, E R \beta)$ were described. Estrogen receptor alpha augmented XREdependent transcription in MCF-7 and T47D breast cancer cells and in HuH7 liver cancer cells (Matthews et al., 2005). Aryl hydrocarbon receptor ligands regulate ER-dependent transcription in cultured cells in an AHR-dependent manner (Kawanishi et al., 2008; Rüegg et al., 2008; Swedenborg et al., 2007). These studies suggest ERs can act as cofactors recruited by AHR. Direct protein-protein interactions between ERs and AHR occurred in vitro (Beischlag and Perdew, 2005; Matthews et al., 2005; Ohtake et al., 2003, 2007) and in vivo in mouse uterine tissue (Ohtake et al., 2003, 2007). These studies demonstrate that nuclear ERs interact with AHR, though it is not well understood whether ERs are constitutive partners of AHR, or if these interactions are ligand- or tissue-dependent.

In this study, we sought to (1) generate and characterize ahr1a and ahr1b single and double mutant zebrafish, and (2) determine whether $a h r 1$ and estrogen receptor genes are required, in addition to $a h r 2$, for TCDD-mediated toxicity in zebrafish embryos. Using pharmacologic and genetic approaches, we found that ahr1 genes are not required for proper fin and craniofacial morphology in adults. Furthermore, neither ahr1 nor estrogen receptor genes are required for TCDD-dependent toxicity in embryos. These results demonstrate that ahrl genes are not required for, and do not compensate for, ahr2 gene function in zebrafish and suggest that ERs are not constitutive partners of AHR.

\section{MATERIALS AND METHODS}

\section{Zebrafish}

Adult zebrafish were raised at $28.5^{\circ} \mathrm{C}$ on a 14 -h light, 10 -h dark cycle in the UAB Zebrafish Research Facility and the BCM Zebrafish Research Facility in an Aquaneering recirculating water system (Aquaneering, Inc, San Diego, California). All zebrafish used for experiments were wild-type $A B$ strain 
(Westerfield, 2000) and all mutant lines were generated on the AB strain. Zebrafish mutant lines for esr2a $a^{\text {uab134 }}$, esr2b ${ }^{\text {uab127 }}$, and gper $^{\text {uab102 }}$ were previously described by Romano et al. (2017). Zebrafish esr $1^{\text {uab119 }}$ mutants were generated in parallel with previously published esr $1^{\text {uab118 }}$ mutants using the same guide RNA (Romano et al., 2017). The esr $1^{\text {uab119 }}$ allele harbors an 11-bp deletion resulting in a frameshift mutation at AA165 and premature stop codon at AA168 in the AF-1 domain. All procedures were approved by the UAB and BCM Institutional Animal Care and Use Committees.

\section{Embryo collection}

Adult zebrafish were allowed to spawn naturally in groups. Embryos were collected in intervals of $10 \mathrm{~min}$ to ensure precise developmental timing and staged following collection, placed in $60 \mathrm{~cm}^{2}$ Petri dishes at a density of no more than 100 per dish in E3B media (60X E3B: $17.2 \mathrm{~g} \mathrm{NaCl}, 0.76 \mathrm{~g} \mathrm{KCl}, 2.9 \mathrm{~g} \mathrm{CaCl}_{2}-2 \mathrm{H}_{2} \mathrm{O}$, $2.39 \mathrm{~g} \mathrm{MgSO}_{4}$ dissolved in $1 \mathrm{l}$ Milli-Q water; diluted to $1 \times$ in 9 1 Milli-Q water plus $100 \mu \mathrm{l} 0.02 \%$ methylene blue), and then stored in an incubator at $28.5^{\circ} \mathrm{C}$ on a 14 -h light, 10 -h dark cycle until treatment.

\section{Embryo treatments}

For chemical exposures to Ahr or estrogen receptor ligands, embryos were manually dechorionated and treated in groups of 850 in $60 \mathrm{~mm}^{2}$ dishes in $7 \mathrm{ml}$ treatment solution beginning at 1 day post fertilization (dpf) until imaging at $3 \mathrm{dpf}$. Dead embryos were removed daily. Drug stocks were prepared in DMSO and diluted to final concentration in E3B as follows: TCDD $(10 \mathrm{ng} / \mathrm{ml}$ [31 nM], AccuStandard, Inc, No. D404N); ICI 182, 780 (Fulvestrant) (10 $\mu \mathrm{M}$, Sigma, No. I4409). DMSO was used as vehicle control $(0.1 \%)$. The concentration of TCDD was chosen as $100 \%$ of wild-type embryos demonstrated robust cardiotoxicity without significant mortality at $3 \mathrm{dpf}$. For chemical exposure to CYP1 ligands, embryos were first treated with TCDD or DMSO as above. At $3 \mathrm{dpf}$, embryos were transferred to 96-well plates (Whatman Microplate Devices, Uniplate clear polystyrene flat bottom, No. 7701-1651), 2-4 embryos per well, in 200 $\mu \mathrm{l}$ treatment solution for $1 \mathrm{~h}$ under light protected conditions at $28^{\circ} \mathrm{C}$. 7-ethoxyresorufin (7-ER) $(1.7 \mu \mathrm{M}$, Sigma, No. E3763) was prepared in DMSO and diluted to final concentration in E3B. DMSO was used as a vehicle control $(0.17 \%)$.

\section{CRISPR-Cas9 mutant generation}

Cas9 mRNA and gRNAs for $a h r 1 a, a h r 1 b$, and $a h r 2$ mutants were generated as previously described for esr 1 , esr $2 a$, esr $2 b$, and gper mutants (Romano et al., 2017). Oligonucleotides containing target site sequences are shown in Table 1. Briefly, oligos were hybridized to generate double-stranded target DNA and annealed into digested pT7-gRNA, then gRNAs were synthesized and purified. Cas9 mRNA was generated using a linearized pT3TSnCas9n plasmid, transcribed, and purified.

For mutant generation, 1-cell-stage embryos were injected using glass needles pulled on a Sutter Instruments Fleming/ Brown Micropipette Puller, model P-97 and a regulated airpressure micro-injector (Harvard Apparatus, New York, PL1-90). Each embryo was injected with a $1 \mathrm{nl}$ solution of $150 \mathrm{ng} / \mu \mathrm{l}$ of Cas9 mRNA, $30 \mathrm{ng} / \mu \mathrm{l}$ of gRNA per target (for a maximum of 2 targets per injection) and $0.1 \%$ phenol red. Mixtures were injected into the yolk of each embryo. At least 100 injected embryos per gRNA pair were raised to adulthood and crossed to wild-type fish (AB strain) to generate F1 embryos. F1 offspring with heritable mutations were sequenced to identify loss of function mutations.

\section{Genotyping}

Genomic DNA was isolated from individual embryos or tail biopsies from individual adult fish by incubation in $50 \mu \mathrm{l} \mathrm{ELB}$ (10 mM Tris $\mathrm{pH} 8.3,50 \mathrm{mM} \mathrm{KCl}, 0.3 \%$ Tween 20) with $0.5 \mu \mathrm{l}$ proteinase $\mathrm{K}(800 \mathrm{U} / \mathrm{ml}, \mathrm{NEB})$ in 96 -well plates, 1 sample per well, at $55^{\circ} \mathrm{C}$ for $8 \mathrm{~h}$. Proteinase $\mathrm{K}$ was inactivated by incubation at $98^{\circ} \mathrm{C}$ for $10 \mathrm{~min}$ and DNA was stored at $-20^{\circ} \mathrm{C}$. Genotyping was performed by PCR and high-resolution melting curve analysis as described by Parant et al. (2009) and Romano et al. (2017). All melting curves were generated with a Bio-Rad CFX96 Real-Time System over a $70-95^{\circ} \mathrm{C}$ range and analyzed with Bio-Rad CFX Manager 3.1 software. All mutations were confirmed by TA cloning and sequencing.

\section{Embryo and larval zebrafish imaging}

All embryos were imaged with a Nikon SMZ25 microscope equipped with a Hamamatsu ORCA-Flash4.0 digital CMOS camera. Images were equally adjusted for brightness and contrast in Adobe Photoshop CC 2018. For imaging of embryo fin and jaw, embryos were fixed at $5 \mathrm{dpf}$ overnight in $4 \%$ formaldehyde in phosphate-buffered saline (PBS) and stored in 70\% ethanol at $-20^{\circ} \mathrm{C}$ until imaging. Embryos were embedded in 3\% methyl cellulose for imaging. Fin length was measured using ImageJ (Schneider et al., 2012) by free-tracing along the edge of each fin and taking the average of left and right fin length for a minimum of $n=8$ fish per genotype. Jaw length was measured in Nikon AR elements software by measuring from the anterior edge of the eyes to the tip of the jaw line as previously described (Teraoka et al., 2002) for a minimum of $n=7$ fish per genotype. Embryos from heterozygous parents were imaged as a mixed clutch and genotyped following imaging. Eye diameter was measured to control for differences in larval size at time of fixation (Parichy et al., 2009). Fin and jaw length measurements from each larva were adjusted for size with a normalization factor created by dividing the mean eye diameter of all embryos by the eye diameter of each individual embryo. Measurements for each embryo were multiplied by this normalization factor for

Table 1. gRNA Targets and Primers for Mutant Generation

\begin{tabular}{lclll}
\hline Gene & Allele Number & \multicolumn{1}{c}{ CRISPR Target } & Oligo 1 & Oligo 2 \\
\hline ahr1a & uab139 & GGAGATAAATATATTGACTTGGG & taGGAGATAAATATATTGACTT & aaacAAGTCAATATATTTATCT \\
ahr1b & uab141 & GGGCAAGCTGGGGTGGCATTTGG & taGGGCAAGCTGGGGTGGCATT & aaacAATGCCACCCCAGCTTGC \\
ahr2 target 1 & uab147 & GGTCTCTGTGCCGTTTGGAGGGG & taGGTCTCTGTGCCGTTTGGAG & aaacCTCCAAACGGCACAGAGA \\
ahr2 target 2 & uab148 & GGATGGCTAAATGACCGGTCAGG & taGGATGGCTAAATGACCGGTC & aaacGACCGGTCATTTAGCCAT \\
esr1 & uab119 & GTCCTCTCAGCAGGCAGCCGTGG & ATTTAGGTGACACTATA & GTTTTAGAGCTAGAAATAGCAAG
\end{tabular}


statistical analysis. For imaging of embryos following TCDD treatment, embryos were imaged in $\mathrm{E} 3 \mathrm{~B}$ in $60 \mathrm{~mm}^{2}$ dishes in $0.02 \%$ tricaine anesthetic. For embryos treated as mixed clutch, embryos were genotyped following imaging.

\section{In vivo CYP1 activity assay}

To measure CYP1 enzyme activity in zebrafish embryos, a modified 7-ER-O-deethylase assay was used (Kais et al., 2017; Nacci et al., 1998; Otte et al., 2010; Verbueken et al., 2018). Embryos were treated from 1 to $3 \mathrm{dpf}$ with $0.1 \%$ DMSO or $10 \mathrm{ng} / \mathrm{ml} \mathrm{TCDD}$, then exposed to $0.17 \%$ DMSO or $1.7 \mu \mathrm{M}$ 7-ER for $1 \mathrm{~h}$. Following exposure, tricaine was added to wells $(0.02 \%$ final concentration) to anesthetize embryos for imaging, and embryos were manually positioned within the well in a single row. Brightfield and fluorescent images of each well were captured with a Nikon SMZ25 microscope equipped with a Hamamatsu ORCA-Flash4.0 digital CMOS camera and Nikon C-FLED2 light source. Resorufin formation, the fluorescent metabolite of 7-ER, was visualized with a TxRed filter set (Chroma, 49008 ET-mCherry, TxRed Filter Set 77074348, $560 \pm 40 \mathrm{~nm}$ excitation/630 $\pm 75 \mathrm{~nm}$ emission). Fluorescence from whole embryos was measured using ImageJ (Schneider et al., 2012) by manually tracing around a single embryo and measuring integrated density. Values were then corrected for background intensity (integrated density-background integrated density $\times$ image area) and normalized to the standard length (SL) of the embryo. Normalization was performed by dividing by the SL of each embryo into the mean SL of all embryos, and multiplying this value by the corrected integrated density value for each embryo.

\section{Adult zebrafish imaging}

Anal and caudal fins from adult zebrafish (8-12 months old) were imaged via brightfield microscopy with a Leica M205 FA microscope equipped with a Leica DFC3000 G camera under $0.01 \%$ tricaine anesthesia. Pectoral fins from adults $(6-7$ months old) were captured from freely swimming, unanesthetized adult zebrafish with a Canon EOS Rebel T5 digital camera and adjusted for brightness and contrast in Adobe Lightroom CC.

\section{Micro-CT analysis}

Adult zebrafish heads (4 per sex per genotype) were collected at 3-6 months postfertilization and fixed overnight (18-24 h) in 4\% formaldehyde in PBS and stored in $70 \%$ ethanol at $-20^{\circ} \mathrm{C}$ until further analysis. For imaging, heads were embedded in $1.5-2 \mathrm{ml}$ microcentrifuge tubes (Fisherbrand, No. 05-408-129 and Genesee, No. 24-283) in 1\% agarose. Scanning was performed on a Bruker SkyScan 1272 Scanner at $50.0 \mathrm{kV} / 200 \mu \mathrm{A}$ with $9 \mu \mathrm{m}$ voxel resolution and $280 \mathrm{~ms}$ exposure time. 3D reconstructions were made with CTVox software and relative skull and jaw lengths were measured in ImageJ.

\section{Experimental design and data analysis}

TCDD exposure experiments were performed on at least 8 embryos from a single clutch per treatment group or vehicle control group. Experiments were performed on 3-5 clutches for each genotype. For ahr1a $a^{\text {uab139 }}, 1$ clutch of maternal zygotic (MZ) embryos was analyzed, and 3 additional clutches were tested as

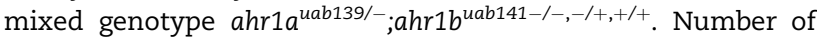
ahr1a uab139/- single mutants and ahr1a $a^{139 /-} ;$ ahr1b $b^{\text {uab141/- }}$ double mutants from each clutch are listed in Table 4. Due to reduced fertility in ahr $2^{\text {uab147 }}$ and esr2buab127 homozygous adults, embryos for these genotypes were derived from breeding heterozygous parents and analyzed as a mixed clutch of embryos (ahr2 $2^{\text {uab147-/-,-/+,+/+ }}$ or esr2buab127-/-,-/+,+/+) where experimenter was blind to genotype; 12-41 embryos from each treatment group for $a h r 2$ mutant clutches were genotyped. One esr $2 b$ mutant clutch was genotyped to confirm presence of homozygous and heterozygous embryos in Mendelian ratios. Other clutches are presumed to contain $25 \%$ homozygous mutants. CYP1 activity experiments were performed on at least 2 embryos per clutch per genotype (2-5 clutches per genotype) for each treatment group. ahr1 and ahr2 mutant embryos treated as mixed clutch (ahr2 $2^{\text {uab147-/-,-/+,+/+ }}$ or ahr1a uab139/-; ahr1buab141-/-,-/+,+/+ ) were genotyped following imaging. ahr2 mutant embryos are on the transgenic tg(gata1:DsRed/-; fli1:GFP/-) background (Ablain et al., 2015; Lawson and Weinstein, 2002; Traver et al., 2003), therefore basal fluorescence is higher at $630 \mathrm{~nm}$ emission in embryos on this background. All ahr2 mutants are compared with heterozygous and wild-type siblings on the same background. ahr1 mutants are compared with wild-type embryos not on a transgenic background. Genotypes were compared using 2-way ANOVA with Tukey's multiple comparisons test where factor 1 is genotype and factor 2 is treatment group. Mean larval fin length and jaw length were measured from at least 7 larvae per genotype. Values were adjusted for eye diameter to control for differences in growth between larvae. Genotypes were compared using 1-way ANOVA with Tukey's multiple comparisons test. Mean ventral skull width and SL of adult zebrafish was used for comparing genotypes by sex using a 2-way ANOVA with Tukey's multiple comparisons test where factor 1 is genotype and factor 2 is sex. Statistical significance was set at $p \leq .05$. GraphPad Prism 8.0.1 software was used for all statistical analyses and for producing graphs.

\section{RESULTS}

\section{Generation of Aryl Hydrocarbon Receptor Mutant Zebrafish}

To compare the function of the 3 zebrafish AHRs (ahr1a, ahr1b, and $a h r 2$ ), we utilized CRISPR-Cas9 technology to generate single and double ahr1 mutants (Figs. 1A and B, Table 1: ahr1a uab139, $a h r 1 b^{\text {uab141 }}$ ) and an ahr2 mutant (Figure 1C, Table 1: ahr2 ${ }^{\text {ua- }}$ b147;uab148). For ahr1a, we generated embryos with a 12-basepair (bp) deletion and 7-bp insertion within the transactivation domain in exon 10, which results in a frameshift mutation at amino acid (AA) 440 and a premature stop codon at AA446. For $a h r 1 b$, we generated embryos with a 7-bp deletion in exon 7, resulting in a frameshift mutation at AA255 and premature stop codon within the ligand binding domain (LBD) at AA271. These guide RNAs were injected simultaneously to generate both single ahr1a uab139 and ahr1buab141 mutants as well as a double ahr1a ${ }^{\text {uab139; }}$;hr1b $b^{\text {uab141 }}$ mutant. Finally, we generated embryos with 2 different mutations in ahr2: uab147 and uab148. Guide RNAs to 2 targets were created: target 1 in exon 2 of the basic helix-loop-helix (bHLH) domain and target 2 in exon 3 upstream of the PAS-A domain. Guide RNAs for each of these targets were injected simultaneously for uab147 (target 1) and uab148 (target 2). The $a h r 2^{\text {uab147 }}$ allele contains a 140 -bp insertion in exon 2 , resulting in a frameshift mutation at AA33 and premature stop codon at AA38 in the bHLH domain. Embryos with this mutation also inherited the mutation for uab148 (5-bp deletion in exon 3 resulting in a frameshift mutation at AA98 and premature stop codon at AA133), although this mutation is downstream of 


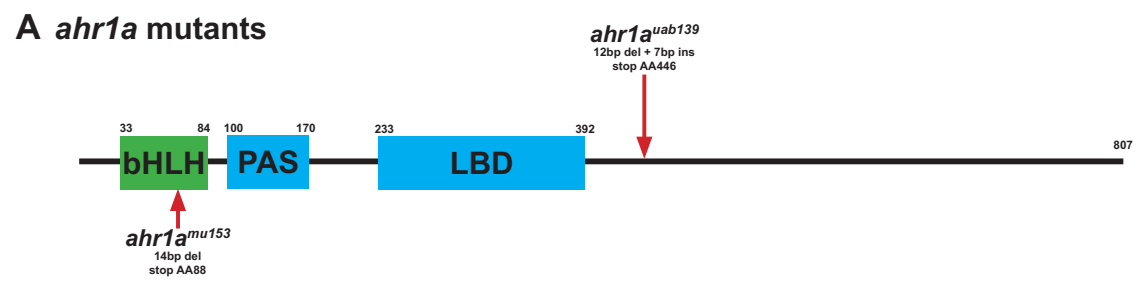

\section{B ahr1b mutants}

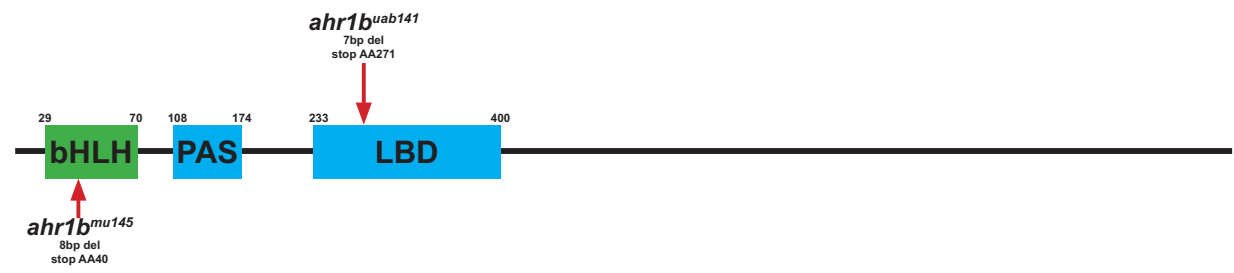

\section{C ahr2 mutants}

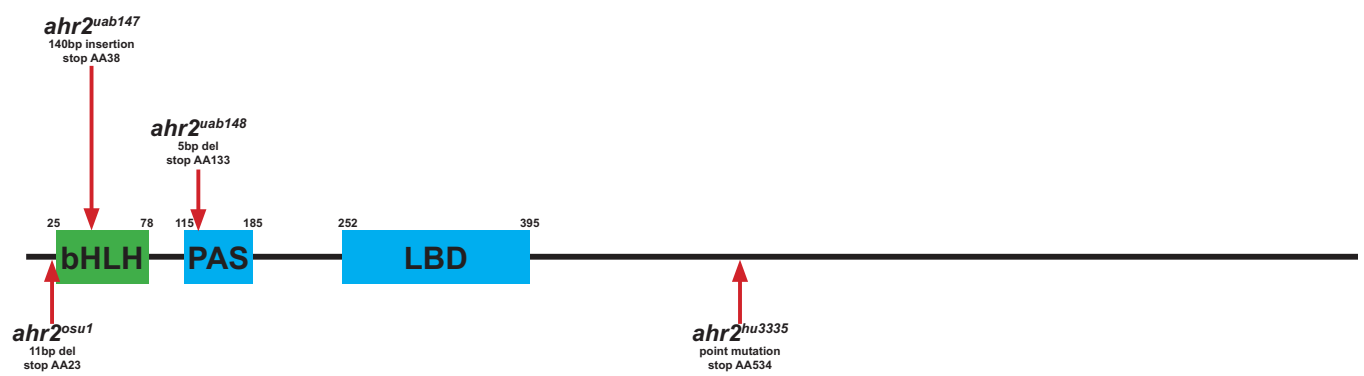

Figure 1. Zebrafish aryl hydrocarbon receptor (AHR) mutants. The amino acid sequence for the zebrafish AHRs 1a (A), 1b (B), and 2 (C) are represented by the black line. Protein domains bHLH, per-arnt-sim (PAS), and ligand binding domain (LBD) are represented by labeled boxes. Numbers indicate the starting and ending point of these domains in the amino acid sequence. Mutations created in each of these receptors are represented by arrows pointing to location of the premature stop codon created by the mutation. Mutants generated for this study are located above each gene, whereas previously published mutants are located below. Abbreviations: bp, DNA basepairs; del, deletion; ins, insertion; AA, amino acid. mu145, mu153 from Sugden et al. (2017); osu1 from Garcia et al. (2018); hu3335 from Goodale et al. (2012).

uab147 and therefore does not influence the mutant transcript. The predicted effect of each of these mutations for ahr1a, ahr1b, and ahr2 is loss of functional protein. Embryos from all mutants were grossly morphologically normal and demonstrated normal mendelian ratios from heterozygous crosses. Maternal zygotic embryos could be derived from homozygous ahr1 single and double mutant parents with natural spawning. In contrast, natural spawning was not observed in ahr2 mutant embryos, consistent with previous studies reporting reduced fertility in ahr2 mutants (Garcia et al., 2018). ahr2 mutant embryos were therefore generated from incrosses of heterozygous ahr2 mutant parents, which demonstrated normal fecundity. Previously published zebrafish ahr mutants are highlighted in Figure 1 for comparison (Garcia et al., 2018; Goodale et al., 2012; Sugden et al., 2017).

\section{Ahr2, But Not Ahr1a or Ahr1b, Is Required for Proper Adult Fin Morphology}

Previous studies have determined that $a h r 2$ is important for proper fin morphology in adult zebrafish (Garcia et al., 2018; Goodale et al., 2012). We therefore first validated our ahr2 mutant line by analyzing fin morphology of adult zebrafish mutants. We found that all ahr $2^{\text {uab147/- }}$ mutant adults of both sexes ( $n=8$ per sex) had severely deformed or absent anal, caudal, and pectoral fins (Figure $2 \mathrm{~F}, \mathrm{~F}^{\prime}, \mathrm{F}^{\prime \prime}$ ) compared with wild-type zebrafish (Figure 2A, A', $\mathrm{A}^{\prime \prime}$ ). This phenotype was consistent among all mutants examined. In contrast, ahr2 heterozygous mutants ( $n=16$ per sex) had normal fin morphology, suggesting that full loss of ahr2 is required to elicit this phenotype (Figure 2E, $E^{\prime}, E^{\prime \prime}$ ). To test whether this phenotype was specifically due to loss of ahr2 function, we analyzed fin morphology in ahr1a uab139/- , ahr1b uab141/- $^{\text {, and ahr1 a } a^{\text {uab139/- }} ; \text { ahr1buab141/- }}$ mutant adult zebrafish ( $n=8$ per sex per genotype). We found that fins developed normally in all mutant males and females (Figs. 2B-D), suggesting that Ahr2 is responsible for proper fin morphology independently of Ahr1a and Ahr1b.

\section{Ahr2, But Not Ahr1a or Ahr1b, Is Required for Proper Adult Craniofacial Morphology}

Previous studies suggested that $a h r 2$ is important for proper craniofacial morphology (Garcia et al., 2018). To explore gross changes in craniofacial morphology in our ahr2 mutants, we performed $\mu \mathrm{CT}$ analysis of adult zebrafish heads at 3-6 months of age. We found that ahr 2 mutant adults ( $n=4$ per sex) have a $29 \%$ or $38 \%$ decreased ventral skull width (in males and females, respectively) as measured by the ratio of the width between the paired opercular bones and paired dentate bones (Figs. 3A, B, K, $\mathrm{L}, \mathrm{O}$, and $\mathrm{P}$; male: wild type $=2.67 \pm 0.11$ [mean $\pm \mathrm{SD}]$, ahr $2^{147 /-}$ $=1.89 \pm 0.09$, mean difference $=0.78, p<.0001$; female: wild type $=2.85 \pm 0.23, a h r 2^{147 /-}=1.90 \pm 0.24$, mean difference $=$ $0.95, p<.0001$; 2-way ANOVA). This ratio measures the width of the broadest part of the caudal skull to the narrowest part of the cranial skull with easily identifiable landmarks on 3D reconstructions from $\mu \mathrm{CT}$ data (Figure 3A). Decreased skull 

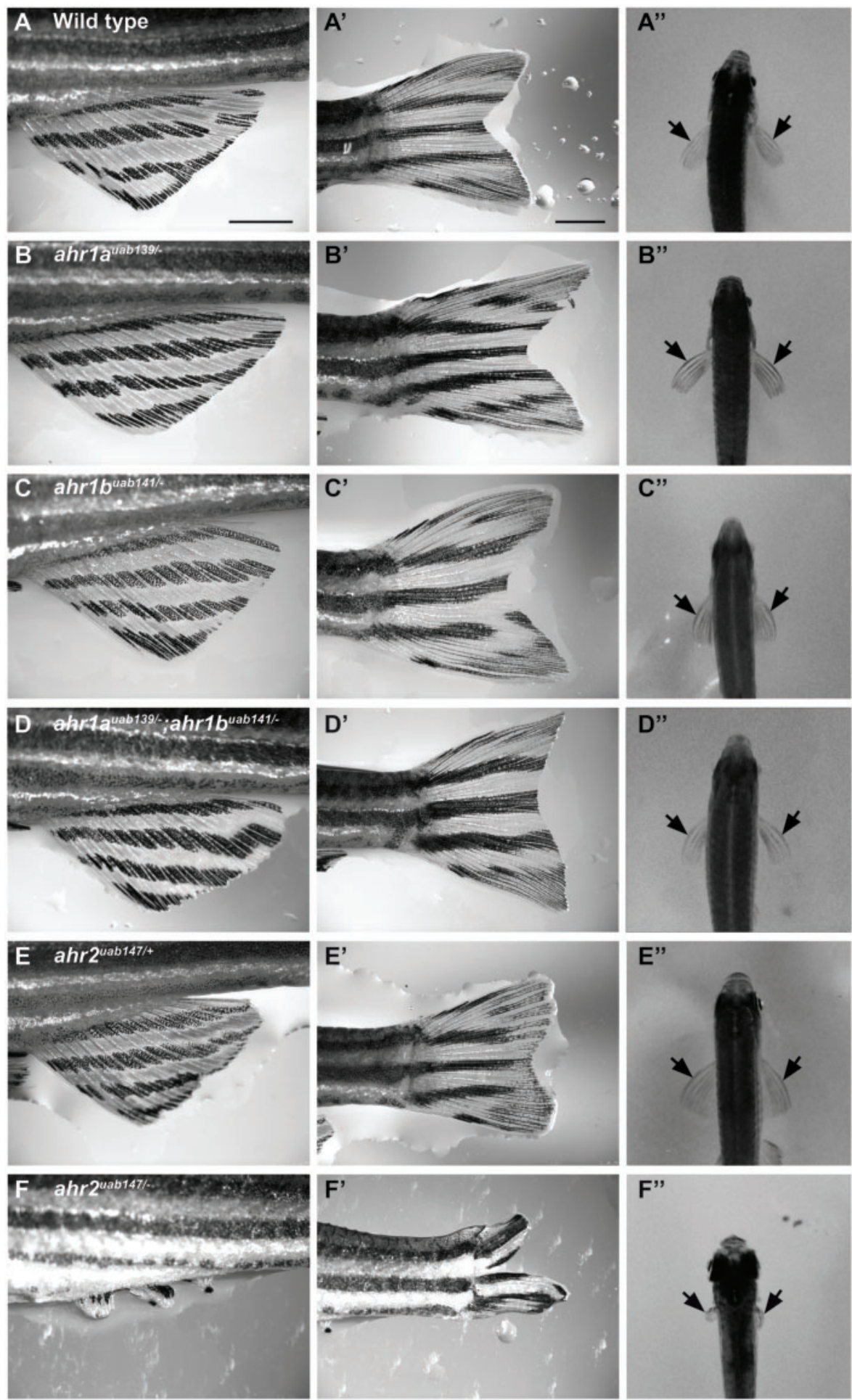

Figure 2. ahr2, but not ahr1 mutants, have abnormal fin morphology. A-F, A'-F', Images of adult male zebrafish with genotype indicated; (A-F), images of the anal fin; $\left(\mathrm{A}^{\prime}-\mathrm{F}^{\prime}\right)$, caudal fin; $\left(\mathrm{A}^{\prime \prime}-\mathrm{F}^{\prime \prime}\right)$, pectoral fins (arrows). Absence of fins and fin deformities are present in anal, caudal, and pectoral fins in ahr2 $-/-$ mutant fish $\left(\mathrm{F}, \mathrm{F}^{\prime}, \mathrm{F}^{\prime \prime}\right)$, but not in ahr1 mutants, ahr $-/+$ mutants, or wild-type fish. Scale bars in panels A and $\mathrm{A}^{\prime}=2 \mathrm{~mm}$ and apply to $\mathrm{B}-\mathrm{F}$ and $\mathrm{B}^{\prime}-\mathrm{F}^{\prime}$, respectively.

width in ahr2 mutants is also observed when measuring this ratio from the frontal view (Figs. $3 \mathrm{C}, \mathrm{D}, \mathrm{Q}, \mathrm{R}, \mathrm{U}$, and V; male: wild type $=2.89 \pm 0.21[$ mean $\pm \mathrm{SD}]$, ahr $2^{147 /-}=2.12 \pm 0.37$, mean difference $=0.77, p=.0001$; female: wild type $=2.79 \pm 0.14$, $a h r 2^{147 /-}=2.36 \pm 0.16$, mean difference $=0.43, p=.02 ; 2$-way ANOVA). To determine if $a h r 1$ genes are also important for proper ventral skull width, we performed $\mu \mathrm{CT}$ analysis of ahr1a;ahr1b double mutant fish. We found no significant difference between ahr1a;ahr1b double mutant zebrafish and wild type in ventral or frontal views (Figs. 3B, D, M, N, S, and T; ventral: $a h r 1 a^{139 /-} ;$ ahr $1 b^{141 /-}$ male $=2.47 \pm 0.16($ mean $\pm \mathrm{SD})$, mean difference $=0.20, p=.21 ;$ ahr1 $a^{139 /-} ; a h r 1 b^{141 /-}$ female $=2.73 \pm$ 

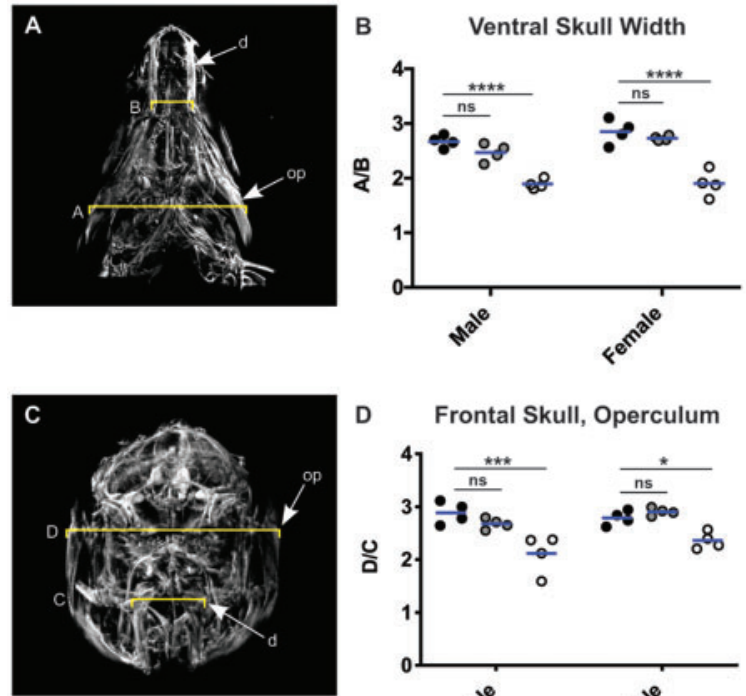

D Frontal Skull, Operculum
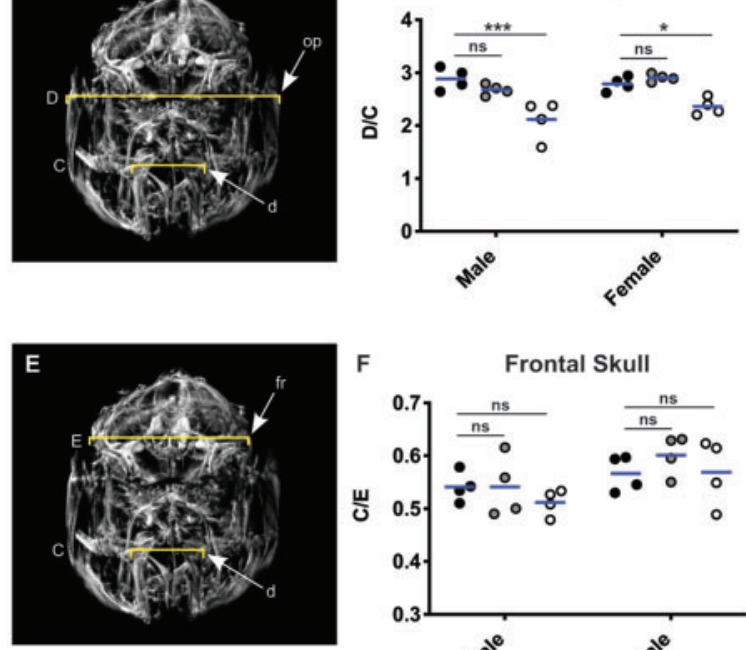

\section{F}

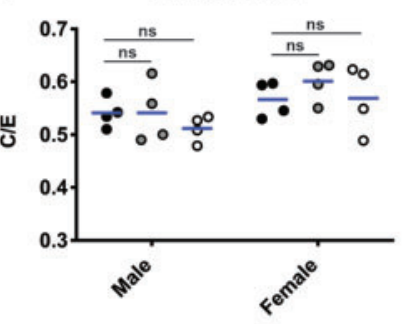

H

Lateral Skull
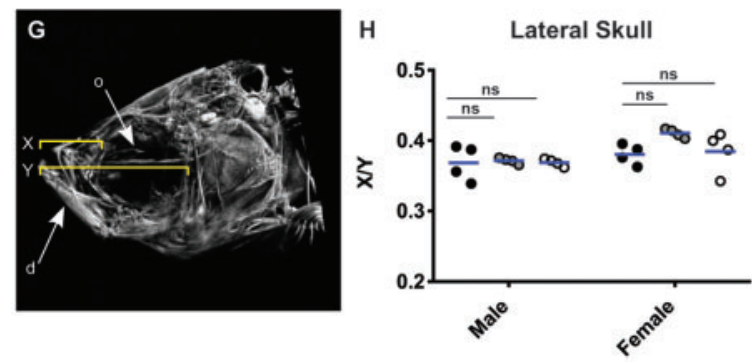

- ahr2uab147/

- wT
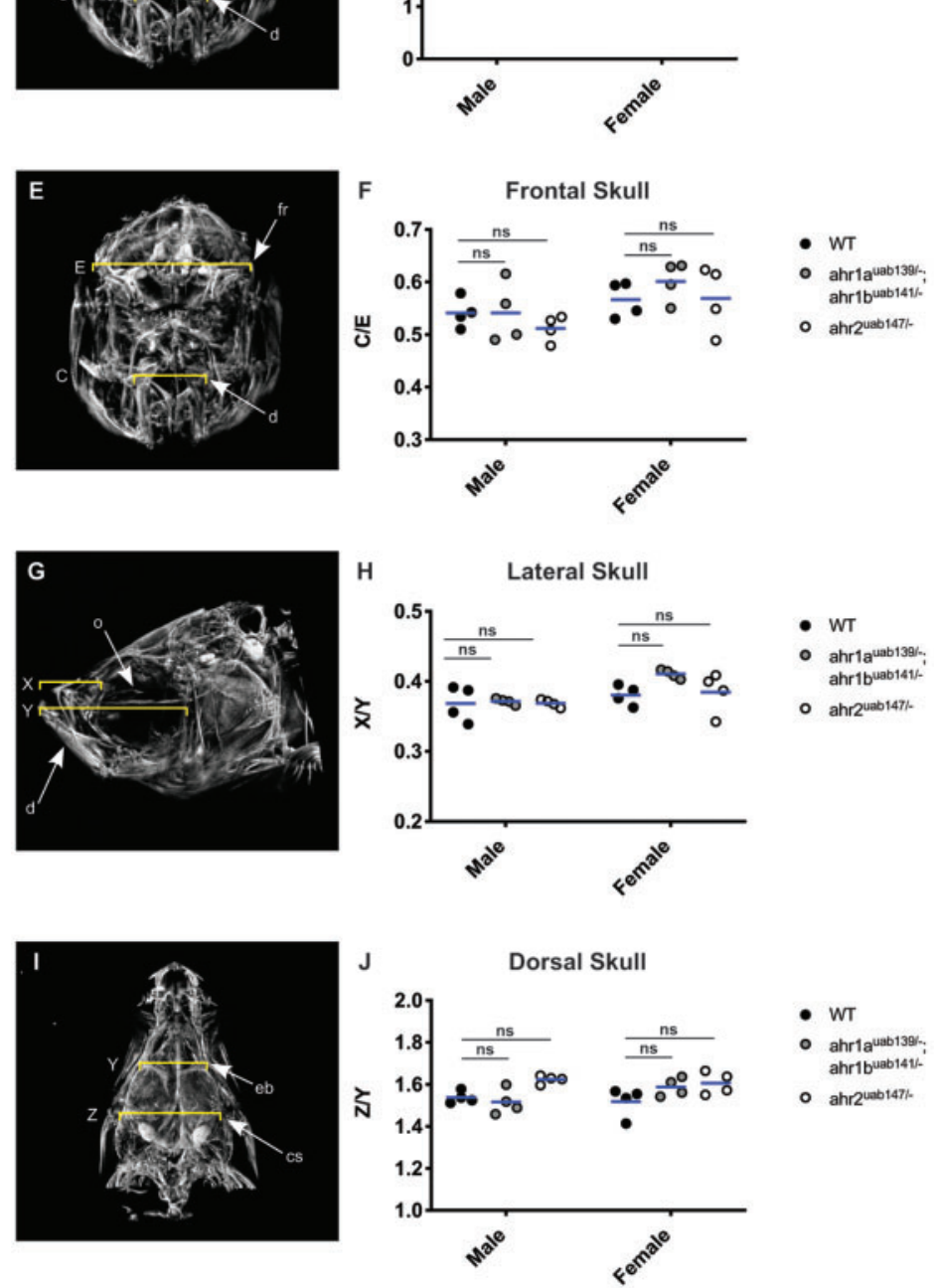

- wT

- ahr1auab139-; ahr1buab141\%

- ahr2uabiatr.

- WT

- ahr1auab139/:; ahr1b $b^{\text {uab } 141 \%-}$

- ahr1auab139ahr2uab147\%.
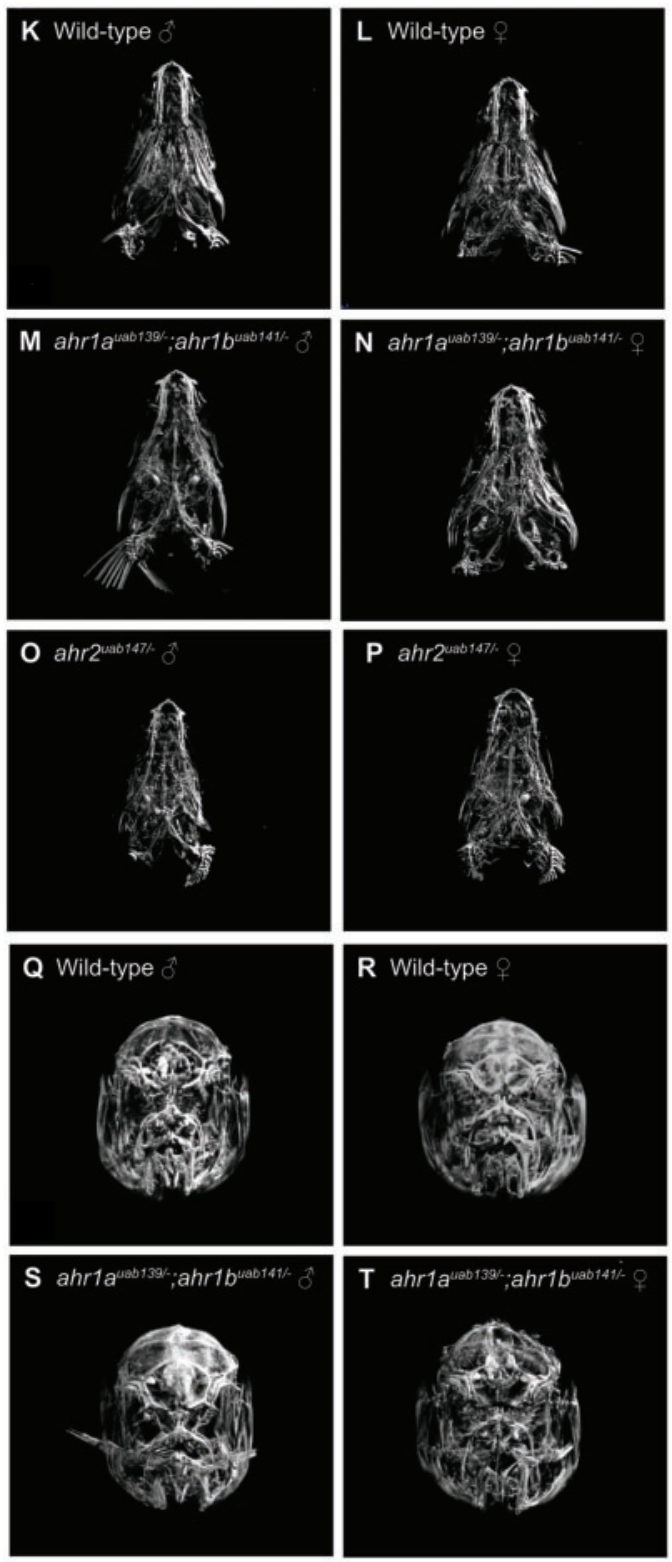

- $\mathrm{WT}$

- ahr1a aab139ahr1 buab14y- ahr2uab147\%
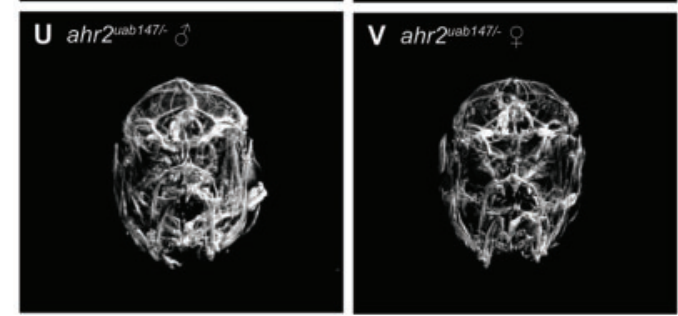

Figure 3. ahr2 but not ahr1 mutant adults have reduced ventral skull width. A-J, Representative micro-CT images of wild-type female (A, C, E, G, I) adult zebrafish heads from ventral, frontal, lateral, and dorsal views. Measurements in graphs (B, D, F, H, J) indicated by horizontal brackets on the wild-type female from panel L. A and B, Ventral skull measurements. $d$, dentate bone; op, opercle; A, width between paired opercle bones; B, width between paired dentate bones. Male and female ahr2, but not ahr1, mutants have reduced A/B ratio compared with wild-type fish. C and D, Frontal skull measurements. d, dentate bone; op, opercle; D, width between paired opercle bones; C, width between paired dentate bones. Male and female ahr2, but not ahr1, mutants have reduced D/C ratio compared with wild-type fish. E and F, Frontal skull measurements. fr, frontal bone; op, opercle; E, width of frontal bone; C, width between paired dentate bones. G and $\mathrm{H}$, Lateral skull measurements. o, orbit; $\mathrm{d}$, dentate bone; $\mathrm{X}$, length between anterior edge of dentate bone and anterior edge of orbit, $\mathrm{Y}$, length between anterior edge of dentate bone and posterior edge of orbit. I and J, Dorsal skull measurements. eb, epiphyseal bar; cs, coronal suture; B, length of epiphyseal bar; Y,length of coronal suture. ${ }^{* * *} p<.001$, ${ }^{* * * *} p<.0001$, ns, not significant ( $p>$.05), 2-way ANOVA with Tukey's multiple comparisons test. K-P, Representative images of ventral skull width in male and female ahr2 and ahr1 mutants. Q$\mathrm{V}$, Representative images of frontal skull width in male and female ahr2 and ahr1 mutants. 
Table 2. SL of Adult Zebrafish Used for $\mu$ CT Analysis

\begin{tabular}{|c|c|c|c|c|c|}
\hline \multirow[t]{2}{*}{ Genotype } & \multirow[t]{2}{*}{ Sex } & \multicolumn{3}{|c|}{$\mathrm{SL}(\mathrm{mm})$} & \multirow[t]{2}{*}{$p$} \\
\hline & & Mean & SD & $n$ & \\
\hline \multirow[t]{2}{*}{ Wild type } & Male & 25.87 & 1.23 & 4 & - \\
\hline & Female & 27.2 & 2.79 & 4 & - \\
\hline \multirow[t]{2}{*}{ ahr1a $a^{\text {uab139/- }}$;ahr1 $b^{\text {uab141/- }}$} & Male & 26.64 & 1.25 & 4 & .84 \\
\hline & Female & 29.56 & 1.93 & 4 & .23 \\
\hline \multirow[t]{2}{*}{$a h r 2^{\text {uab147/- }}$} & Male & 22.47 & 1.8 & 4 & .06 \\
\hline & Female & 25.42 & 2.29 & 4 & .42 \\
\hline
\end{tabular}

Fish are grouped by sex and genotype ( $n=4$ individuals per group). Mean and standard deviation are reported in $\mathrm{mm} . p$ Value describes comparison between mutant and wild-type fish of the same sex. Two-way ANOVA with Tukey's multiple comparisons.

0.04 , mean difference $=0.12, p=.56 ; 2$-way ANOVA); frontal: ahr1 $a^{139 /-} ; a h r 1 b^{141 /-}$ male $=2.68 \pm 0.10($ mean $\pm \mathrm{SD})$, mean difference $=0.21, p=.33 ;$ ahr1 $a^{139 /-} ;$ ahr1 $b^{141 /-}$ female = $2.91 \pm 0.07$, mean difference $=-0.12, p=.69 ; 2$-way ANOVA).

To test for less obvious craniofacial defects in ahr mutants, we also measured additional parameters from $\mu \mathrm{CT}$ images in frontal, lateral, and dorsal views. We found no significant difference in frontal skull width (Figs. 3E and F), lateral jaw extension (Figs. 3G and H), or dorsal skull width (Figs. 3I and J) between wild-type and ahr1 or ahr2 mutants of either sex (2-way ANOVA, $p>.05$ for all comparisons). Images of all mutants examined from ventral, frontal, lateral, and dorsal views are shown in Supplementary Figure 1.

It is possible that the reduced skull width observed in ahr2 mutants is due to a general growth defect. To test for a growth defect, we analyzed SL (Parichy et al., 2009), an established parameter of growth and development. We found no significant difference in SL between wild-type and ahr1 or ahr2 mutants of the same sex (Table 2). These results suggest that Ahr2 regulates craniofacial morphology independently of Ahr1a and Ahr1b.

\section{Aryl Hydrocarbon Receptors Are Not Required for Larval Fin Growth}

Because we observed fin defects in ahr2 mutant adult zebrafish, we tested whether fin defects were present in larval development. We compared the length of the pectoral fins at $5 \mathrm{dpf}$ in $a h r 2$, ahr1a, ahr1b, and ahr1a;ahr1b mutant and wild-type larvae. All measurements were corrected for embryo size using eye diameter (Table 3). We found no significant difference in pectoral fin length between ahr2 mutant and wild-type larvae (Table 3, Figs. 4A, E, and G; wild type $=472.9 \pm 9.0 \mu \mathrm{m}$ [mean $\pm \mathrm{SD}$ ], ahr $2^{\text {uab147/- }}=464.0 \pm 29.49 \mu \mathrm{m}, p=.85$, 1 -way ANOVA). We next compared pectoral fin length between ahr1 mutants and wildtype larvae, and saw no significant difference (Table 3, Figs. 4A$\mathrm{D}$ and $\mathrm{G}$; $a h r 1 a^{\text {uab139/- }}=461.4 \pm 22.2 \mu \mathrm{m}, p=.68$; ahr1b $b^{\text {uab141/- }}=$ $497.4 \pm 18.29 \mu \mathrm{m}, p=.06$; ahr1 $a^{\text {uab139/- }}$; ahr1b ${ }^{\text {uab141/- }}=471.1 \pm$ $23.21 \mu \mathrm{m}, p=.9997)$. These results suggest that AHRs are not required for embryonic fin development.

\section{Aryl Hydrocarbon Receptors Are Not Required for Larval Jaw Growth}

Because we observed changes in craniofacial morphology in ahr2 mutants, we also compared the craniofacial morphology of ahr1a;ahr1b and ahr2 mutant and wild-type larvae at $5 \mathrm{dpf}$. Because the skull is mostly cartilaginous at this developmental stage and opercular bones are not fully formed, we instead compared morphology by measuring the length of the jaw from the anterior tip of the eye to the end of the jaw, as has been previously used to compare jaw growth in embryos (Teraoka et al., 2002). All values were corrected for larval size using eye diameter (Table 3). When comparing jaw length between ahr $2^{\text {uab147/- }}$ mutant and wild-type larvae, we found no significant difference (Table 3, Figs. 4A, E, and H; wild type $=91.09 \pm 7.02 \mu \mathrm{m}$ [mean \pm $\mathrm{SD}$, ahr $2^{\text {uab147/- }}=91.78 \pm 9.71 \mu \mathrm{m}, p=.9998$, 1-way ANOVA). We next compared jaw length between ahr1 mutant and wildtype larvae, and did not observe a significant difference compared with wild type in single or double ahr1 mutants (Table 3, Figs. 4A-D and $\mathrm{H}$; ahr1a aab139/- $=101.4 \pm 6.08 \mu \mathrm{m}, p=.12$; ahr1b $b^{\text {uab141/- }}=94.83 \pm 10.29 \mu \mathrm{m}, \quad p=.91$; ahr1a $a^{\text {uab139/- }}$;ahr1b $\left.b^{\text {uab141/- }}=100.3 \pm 17.04 \mu \mathrm{m}, p=.30\right)$. These results suggest that AHRs are not required for embryonic jaw growth.

\section{Ahr2, But Not Ahr1a or Ahr1b, Is Required for TCDD- induced Cardiotoxicity in Embryos}

2,3,7,8-tetrachlorodibenzo-p-dioxin is a persistent environmental toxin that acts as a carcinogen in humans and causes cardiotoxicity and mortality at nanomolar concentrations in zebrafish embryos (Belair et al., 2001; Flesch-Janys et al., 1995; Henry et al., 1997). Ahr2 is known to mediate the toxic effects of TCDD (Garcia et al., 2018; Goodale et al., 2012; Tanguay et al., 1999), yet it is not clear whether zebrafish ahr1 genes are also required for TCDD toxicity. To test this, we exposed zebrafish with mutations in each of the AHRs (ahr2, ahr1a, ahr1b) and ahr1a;ahr1b double mutants to TCDD. 100\% of ahr1a and ahr1b single and double mutants (3-4 clutches per genotype, 3-28 embryos per clutch) demonstrated severe PCE and abnormal heart looping, which are characteristic of TCDD toxicity in wild-type embryos at $3 \mathrm{dpf}$ (Table 4, Figs. 5A-H and N). In contrast, 100\% of ahr2 homozygous mutants ( 5 clutches, 4-16 embryos per clutch) were resistant to TCDD toxicity (Table 4, Figs. 5I, J, N, and O). One hundred percent of ahr $2-/+$ and $+/+$ embryos from the same clutches (5 clutches, 8-26 embryos per clutch) also demonstrated TCDD toxicity or mortality at $3 \mathrm{dpf}$, suggesting a single copy of $a h r 2$ is sufficient to induce TCDD toxicity (Table 4, Figs. $5 \mathrm{~K}, \mathrm{~L}, \mathrm{~N}$, and $\mathrm{O}$ ). Less than $16 \%$ mortality was observed in all DMSO-treated embryos from the same clutches and $\leq 17 \%$ of DMSO-treated embryos exhibited PCE or abnormal heart looping at $3 \mathrm{dpf}$ (Table 4, Figure $5 \mathrm{M}$ ), providing evidence that observed cardiotoxicity is specific to TCDD treatment and not a side effect of mutation. Overall, these results suggest that Ahr1a and Ahr1b are not required for TCDD toxicity.

\section{Ahr2, But Not Ahr1a or Ahr1b, Is Required for TCDD- induced CYP1 Activity in Embryos}

To provide additional evidence that $a h r 2$ acts independently of ahr1 receptors to mediate TCDD-induced toxicity, we assayed activity of CYP1A, a protein upregulated by AHR following TCDD exposure (Andreasen, Spitsbergen, et al., 2002; Otte et al., 2010; Verbueken et al., 2018). We hypothesized that ahr2 -/- embryos would demonstrate significantly reduced CYP1 activity, whereas ahr1 mutant embryos would demonstrate normal CYP1 activity due to retained function of ahr2. To assay CYP1A activity, we exposed embryos to 7-ER, which is metabolized by the $1 \mathrm{~A}$ family of cytochrome-P450 enzymes into a fluorescent metabolite, resorufin (Nacci et al., 1998), and quantified fluorescence in live embryos (Figure 6A). We found that $a h r 2-/-$ 
Table 3. Embryo Fin and Jaw Length Normalized to Eye Diameter

\begin{tabular}{|c|c|c|c|c|c|c|c|}
\hline Genotype & Embryo & $\begin{array}{l}\text { Eye Diameter } \\
(\mu \mathrm{m})\end{array}$ & $\begin{array}{c}\text { Normalization } \\
\text { Factor }\end{array}$ & $\begin{array}{l}\text { Raw Fin } \\
\text { Length } \\
(\mu \mathrm{m})\end{array}$ & $\begin{array}{l}\text { Corrected Fin } \\
\text { Length }(\mu \mathrm{m})\end{array}$ & $\begin{array}{c}\text { Raw Jaw } \\
\text { Length }(\mu \mathrm{m})\end{array}$ & $\begin{array}{c}\text { Corrected Jaw } \\
\text { Length }(\mu \mathrm{m})\end{array}$ \\
\hline \multirow[t]{13}{*}{ Wild-type } & 1 & 370.1 & 0.98 & 473.5 & 462.3 & 95.0 & 92.7 \\
\hline & 2 & 363.3 & 0.99 & 477.5 & 474.9 & 91.2 & 90.7 \\
\hline & 3 & 351.9 & 1.03 & 452.7 & 464.8 & 85.1 & 87.4 \\
\hline & 4 & 362.6 & 1.00 & 480.4 & 478.7 & 85.1 & 84.8 \\
\hline & 5 & 363.1 & 1.00 & 483.4 & 481.1 & 90.4 & 89.9 \\
\hline & 6 & 363.0 & 1.00 & 466.9 & 464.7 & 80.8 & 80.5 \\
\hline & 7 & 371.5 & 0.97 & 473.3 & 460.3 & 86.3 & 83.9 \\
\hline & 8 & 369.8 & 0.98 & 485.9 & 474.8 & 110.5 & 107.9 \\
\hline & 9 & 352.2 & 1.03 & 466.2 & 478.3 & 92.3 & 94.7 \\
\hline & 10 & 353.9 & 1.02 & 468.2 & 478.0 & 91.2 & 93.1 \\
\hline & 11 & 358.5 & 1.01 & 487.3 & 491.1 & 98.0 & 98.8 \\
\hline & 12 & 350.1 & 1.03 & 450.1 & 464.5 & 85.3 & 88.0 \\
\hline & 13 & 369.5 & 0.98 & 485.2 & 474.4 & 93.9 & 91.8 \\
\hline Wild-type average & & 361.5 & & 473.1 & 472.9 & 91.2 & 91.1 \\
\hline \multirow[t]{10}{*}{ ahr1a $a^{u a b 139 /-}$} & 1 & 370.8 & 0.97 & 430.2 & 419.3 & 114.1 & 111.2 \\
\hline & 2 & 383.8 & 0.94 & 512.1 & 482.2 & 108.6 & 102.3 \\
\hline & 3 & 351.5 & 1.03 & 442.7 & 455.1 & 92.3 & 94.9 \\
\hline & 4 & 375.0 & 0.96 & 478.8 & 461.4 & 111.9 & 107.8 \\
\hline & 5 & 360.3 & 1.00 & 488.1 & 489.5 & 106.3 & 106.6 \\
\hline & 6 & 364.3 & 0.99 & 484.0 & 480.1 & 100.6 & 99.7 \\
\hline & 7 & 357.2 & 1.01 & 425.3 & 430.2 & 91.6 & 92.6 \\
\hline & 8 & 364.5 & 0.99 & 465.2 & 461.2 & 105.0 & 104.1 \\
\hline & 9 & 361.4 & 1.00 & 469.0 & 468.9 & 98.4 & 98.4 \\
\hline & 10 & 360.3 & 1.00 & 464.8 & 466.2 & 95.8 & 96.0 \\
\hline ahr1a $a^{\text {uab139/- }}$ average & & 364.9 & & 466.0 & 461.4 & 102.4 & 101.4 \\
\hline \multirow[t]{10}{*}{$a h r 1 b^{u a b 141 /-}$} & 1 & 368.5 & 0.98 & 483.4 & 474.0 & 97.9 & 96.0 \\
\hline & 2 & 349.4 & 1.03 & 457.2 & 472.8 & 99.9 & 103.3 \\
\hline & 3 & 372.7 & 0.97 & 500.0 & 484.7 & not measured & \\
\hline & 4 & 366.2 & 0.99 & 518.1 & 511.2 & 106.2 & 104.7 \\
\hline & 5 & 352.7 & 1.02 & 497.6 & 509.8 & 102.7 & 105.2 \\
\hline & 6 & 369.2 & 0.98 & 528.1 & 516.9 & 83.3 & 81.6 \\
\hline & 7 & 362.3 & 1.00 & 476.3 & 475.0 & 87.0 & 86.8 \\
\hline & 8 & 352.0 & 1.03 & 497.6 & 510.8 & 92.0 & 94.4 \\
\hline & 9 & 369.4 & 0.98 & 520.1 & 508.8 & 80.4 & 78.6 \\
\hline & 10 & 364.4 & 0.99 & 514.5 & 510.3 & 103.8 & 102.9 \\
\hline ahr1 ${ }^{\text {buab141/- }}$ average & & 362.7 & & 499.3 & 497.4 & 94.8 & 94.8 \\
\hline \multirow[t]{8}{*}{ ahr1a $a^{\text {uab139/- }} ;$ ahr1b $b^{\text {uab141- }}$} & 1 & 359.0 & 1.01 & 489.5 & 492.6 & 104.9 & 105.5 \\
\hline & 2 & 346.0 & 1.04 & 449.9 & 469.7 & 86.9 & 90.7 \\
\hline & 3 & 342.2 & 1.06 & 463.2 & 489.1 & 117.7 & 124.2 \\
\hline & 4 & 354.7 & 1.02 & 475.8 & 484.7 & 101.7 & 103.6 \\
\hline & 5 & 352.2 & 1.03 & 455.8 & 467.6 & 99.1 & 101.7 \\
\hline & 6 & 335.8 & 1.08 & 389.3 & 418.9 & 64.0 & 68.8 \\
\hline & 7 & 365.7 & 0.99 & 484.1 & 478.2 & not measured & \\
\hline & 8 & 348.3 & 1.04 & 450.8 & 467.7 & 103.3 & 107.2 \\
\hline ahr1a uab139/- $; a h r 1 b^{\text {uab141/- }}$ average & & 350.5 & & 457.3 & 471.1 & 96.8 & 100.3 \\
\hline \multirow[t]{10}{*}{$a h r 2^{u a b 147 /-}$} & 1 & 350.2 & 1.03 & 461.0 & 475.7 & 89.4 & 92.3 \\
\hline & 2 & 365.6 & 0.99 & 513.0 & 507.0 & 107.1 & 105.9 \\
\hline & 3 & 384.8 & 0.94 & 494.9 & 464.7 & 94.2 & 88.4 \\
\hline & 4 & 359.3 & 1.01 & 473.8 & 476.7 & 107.8 & 108.4 \\
\hline & 5 & 365.5 & 0.99 & 473.9 & 468.5 & 100.2 & 99.0 \\
\hline & 6 & 367.6 & 0.98 & 428.7 & 421.4 & 92.2 & 90.6 \\
\hline & 7 & 368.1 & 0.98 & 490.7 & 481.6 & 87.7 & 86.1 \\
\hline & 8 & 364.1 & 0.99 & 412.0 & 408.8 & 80.8 & 80.2 \\
\hline & 9 & 357.9 & 1.01 & 478.4 & 483.0 & 82.0 & 82.8 \\
\hline & 10 & 365.7 & 0.99 & 458.2 & 452.8 & 85.2 & 84.2 \\
\hline ahr $2^{\text {uab147/- }}$ average & & 364.9 & & 468.5 & 464.0 & 92.6 & 91.8 \\
\hline
\end{tabular}

Total embryo average

361.3

Embryos are grouped by genotype with 7-13 embryos per group. All embryos were fixed at 5 dpf prior to imaging. The eye diameter for each embryo was measured, then the average eye diameter of all embryos was calculated ("Total embryo average"). To create a normalization factor for each embryo, the total embryo average eye diameter was divided by the individual embryo eye diameter. The normalization factor was then multiplied by the raw fin length or raw jaw length values to create corrected values for each measurement. Corrected values were used in all statistical analyses. 

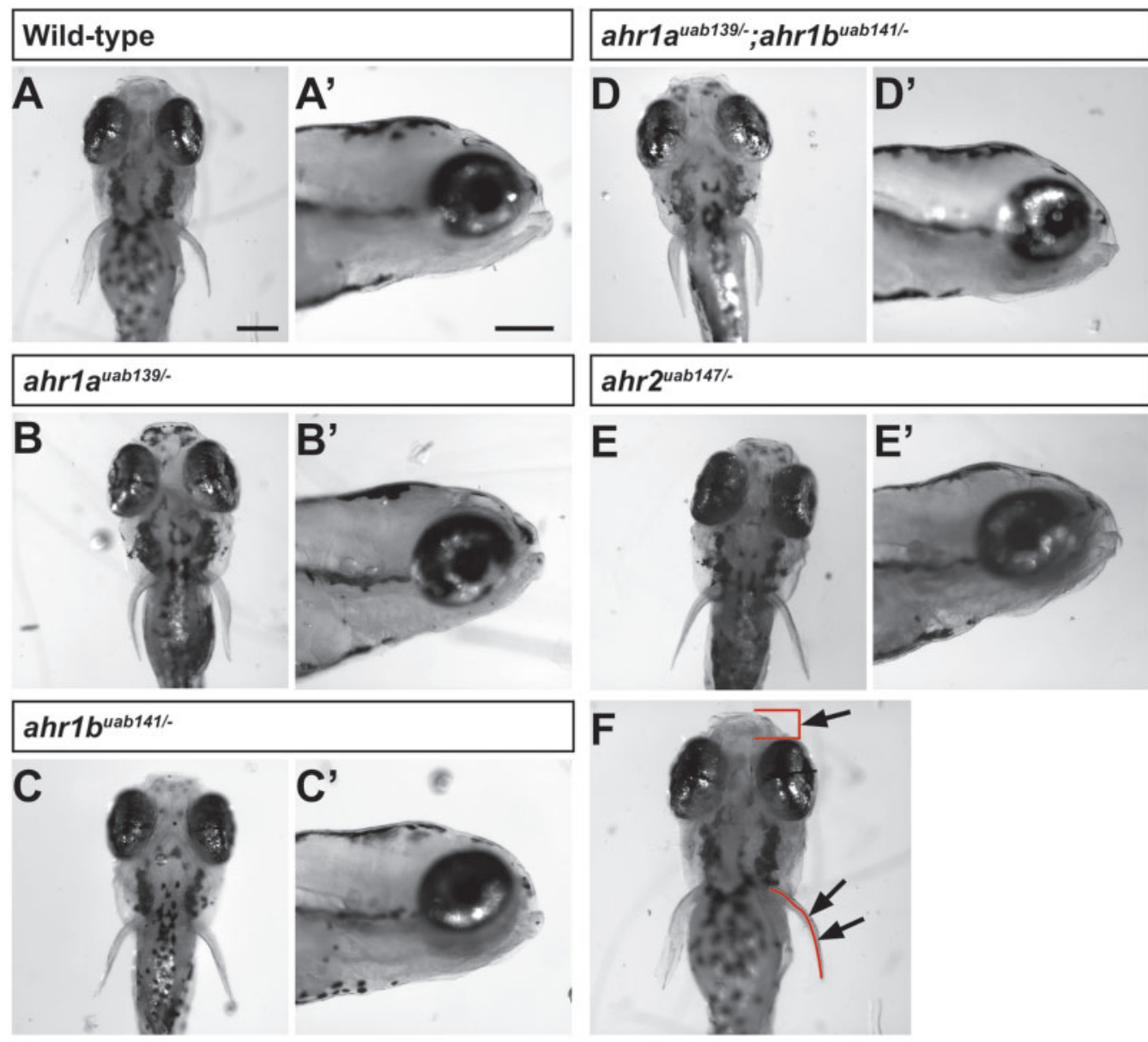

G

Fin Length

$\mathbf{H}$
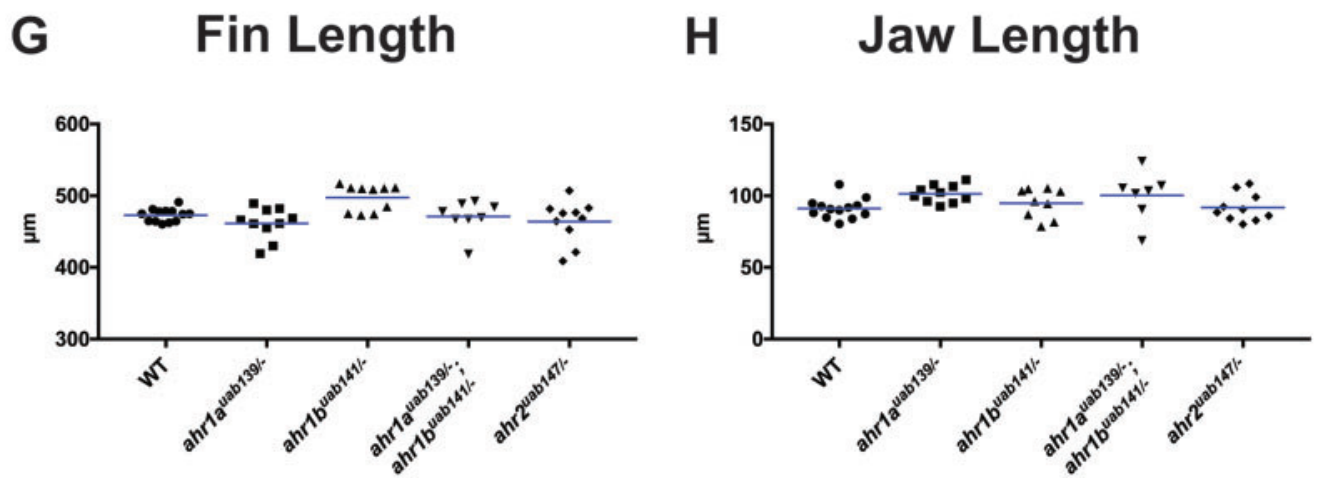

Figure 4. ahr1 and ahr2 mutant larvae have normal fin and jaw morphology. A-E, Representative images of jaw and fin morphology for wild-type, ahr1, and ahr2 mutant larvae at 5 days post fertilization. A-E, Embryo head and pectoral fins, ventral view. $\left(\mathrm{A}^{\prime}-\mathrm{E}^{\prime}\right)$ Jaw profile, sagittal view. F, Example measurements used for data in graphs quantifying fin (G) and jaw (H) length. Arrows point to regions measured for fin and jaw length quantification outlined for clarification. There is no significant difference in fin length or jaw length in ahr1 or ahr2 mutant larvae compared with wild type. $p>.05$, 1-way ANOVA with Tukey's multiple comparisons test. Scale bars in A and A' $=200 \mu \mathrm{m}$ and apply to panels $\mathrm{B}-\mathrm{E}$ and $\mathrm{B}^{\prime}-\mathrm{E}^{\prime}$, respectively. Fin and jaw lengths were corrected for standard length of each fish using eye diameter.

embryos exposed to TCDD+7-ER had significantly reduced resorufin formation as measured by whole embryo fluorescence compared with heterozygous and wild-type siblings (Figs. 6F, I, and $\mathrm{K}$; $\mathrm{ahr} 2^{\text {uab147/- }}=4.11 \mathrm{e} 8 \pm 1.75 \mathrm{e} 8 \mu \mathrm{m}^{2}$ [mean $\pm \mathrm{SD}$, integrated density]; ahr $2^{\text {uab147/+ }}=1.31 \mathrm{e} 9 \pm 5.09 \mathrm{e} 8 \mu \mathrm{m}^{2}$, mean difference $=$ $9.02 \mathrm{e} 8, p<.0001 ; a^{2} 2^{+}=1.35 \mathrm{e} 9 \pm 3.92 \mathrm{e} 8 \mu \mathrm{m}^{2}$, mean difference $=9.40 \mathrm{e} 8, p<.0001 ; 2$-way ANOVA). In contrast, we found that ahr1a;ahr1b double mutant embryos exposed to TCDD+7-ER had no significant difference in resorufin formation compared with wild-type embryos at $3 \mathrm{dpf}$ (Figs. 6B-E and J; ahr1a $a^{\text {uab139/- }}$;ahr1b ${ }^{\text {uab141/- }}=1.28 \mathrm{e} 9 \pm 2.09 \mathrm{e} 8 \mu \mathrm{m}^{2} ; \mathrm{WT}=1.13 \mathrm{e} 9 \pm$ $2.79 \mathrm{e} 8 \mu \mathrm{m}^{2}$, mean difference $=1.51 \mathrm{e} 8, p=.41$; 2-way ANOVA).

Furthermore, fluorescence was not significantly increased in TCDD versus DMSO treated $a h r 2$-/- embryos exposed to 7-ER (Figure 6K; DMSO+7-ER: 1.57e8 $\pm 8.05 \mathrm{e} 7 \mu^{2}{ }^{2}$, mean difference $=$ 2.53e8, $p=.30$; 2-way ANOVA), whereas heterozygous and wildtype siblings had significantly increased fluorescence in TCDD versus DMSO-treated embryos exposed to 7-ER (Figure 6K; DMSO+7-ER: $a h r 2^{\text {uab147/+ }}=1.41 \mathrm{e} 8 \pm 5.08 \mathrm{e} 7 \mu \mathrm{m}^{2}$, mean difference $=1.17 \mathrm{e} 9, p<.0001 ; \mathrm{ahr}^{+}=1.56 \mathrm{e} 8 \pm 4.15 \mathrm{e} 7 \mu \mathrm{m}^{2}$, mean 
Table 4. TCDD Toxicity in Ahr1, Ahr2, and Estrogen Receptor Mutant Embryos

\begin{tabular}{|c|c|c|c|c|c|c|c|}
\hline Genotype & Clutch & Treatment & $n$ & \%PCE, $3 \mathrm{dpf}$ & $\begin{array}{l}\text { \%Mortality, } \\
3 \mathrm{dpf}\end{array}$ & $\begin{array}{l}\text { \%Normal, } \\
3 \mathrm{dpf}\end{array}$ & Notes \\
\hline \multirow[t]{18}{*}{ Wild type } & \multirow[t]{2}{*}{1} & $0.1 \%$ DMSO & 25 & 0 & 12 & 88 & Pictured in Figures 5 and 6 \\
\hline & & $10 \mathrm{ng} / \mathrm{ml} \mathrm{TCDD}$ & 25 & 88 & 12 & 0 & Pictured in Figure 6 \\
\hline & \multirow[t]{2}{*}{2} & $0.1 \%$ DMSO & 23 & 0 & 0 & 100 & \\
\hline & & $10 \mathrm{ng} / \mathrm{ml} \mathrm{TCDD}$ & 22 & 73 & 27 & 0 & \\
\hline & \multirow[t]{2}{*}{3} & $0.1 \%$ DMSO & 24 & 0 & 0 & 100 & \\
\hline & & $10 \mathrm{ng} / \mathrm{ml} \mathrm{TCDD}$ & 25 & 100 & 0 & 0 & \\
\hline & \multirow[t]{4}{*}{4} & $0.1 \%$ DMSO & 15 & 0 & 0 & 100 & Pictured in Figure 6 \\
\hline & & $10 \mathrm{ng} / \mathrm{ml} \mathrm{TCDD}$ & 15 & 100 & 0 & 0 & Pictured in Figure 6 \\
\hline & & $10 \mu \mathrm{M}$ ICI-182, 780 & 15 & 0 & 0 & 100 & Pictured in Figure 6 \\
\hline & & $\begin{array}{c}10 \mu \mathrm{M} \mathrm{ICI}-182,780+ \\
10 \mathrm{ng} / \mathrm{ml} \mathrm{TCDD}\end{array}$ & 15 & 100 & 0 & 0 & Pictured in Figure 6 \\
\hline & \multirow[t]{4}{*}{5} & $0.1 \%$ DMSO & 15 & 0 & 0 & 100 & \\
\hline & & $10 \mathrm{ng} / \mathrm{ml} \mathrm{TCDD}$ & 15 & 100 & 0 & 0 & \\
\hline & & $10 \mu \mathrm{M}$ ICI-182, 780 & 15 & 0 & 7 & 93 & \\
\hline & & $\begin{array}{c}10 \mu \mathrm{M} \mathrm{ICI}-182,780+ \\
10 \mathrm{ng} / \mathrm{ml} \mathrm{TCDD}\end{array}$ & 15 & 93 & 7 & 0 & \\
\hline & \multirow[t]{4}{*}{6} & $0.1 \%$ DMSO & 15 & 0 & 0 & 100 & \\
\hline & & $10 \mathrm{ng} / \mathrm{ml} \mathrm{TCDD}$ & 15 & 93 & 7 & 0 & \\
\hline & & $10 \mu \mathrm{M}$ ICI-182, 780 & 15 & 7 & 0 & 93 & \\
\hline & & $\begin{array}{c}10 \mu \mathrm{M} \mathrm{ICI}-182,780+ \\
10 \mathrm{ng} / \mathrm{ml} \mathrm{TCDD}\end{array}$ & 15 & 100 & 0 & 0 & \\
\hline \multirow[t]{2}{*}{ MZahr1a uab139/- } & \multirow[t]{2}{*}{1} & $0.1 \%$ DMSO & 24 & 0 & 8 & 92 & Pictured in Figure 5 \\
\hline & & $10 \mathrm{ng} / \mathrm{ml} \mathrm{TCDD}$ & 24 & 92 & 8 & 0 & Pictured in Figure 5 \\
\hline \multirow[t]{6}{*}{ MZahr1b ${ }^{\text {uab141/- }}$} & \multirow[t]{2}{*}{2} & $0.1 \%$ DMSO & 14 & 0 & 7 & 93 & Pictured in Figure 5 \\
\hline & & $10 \mathrm{ng} / \mathrm{ml} \mathrm{TCDD}$ & 14 & 93 & 7 & 0 & Pictured in Figure 5 \\
\hline & \multirow[t]{2}{*}{3} & $0.1 \%$ DMSO & 23 & 0 & 4 & 96 & \\
\hline & & $10 \mathrm{ng} / \mathrm{ml} \mathrm{TCDD}$ & 23 & 96 & 4 & 0 & \\
\hline & \multirow[t]{2}{*}{4} & $0.1 \%$ DMSO & 25 & 0 & 4 & 96 & \\
\hline & & $10 \mathrm{ng} / \mathrm{ml} \mathrm{TCDD}$ & 25 & 92 & 8 & 0 & \\
\hline \multirow[t]{8}{*}{ MZahr1a $a^{\text {uab139/- }}$;MZahr1b ${ }^{\text {uab141/- }}$} & \multirow[t]{2}{*}{5} & $0.1 \%$ DMSO & 23 & 17 & 13 & 70 & Pictured in Figure 5 \\
\hline & & $10 \mathrm{ng} / \mathrm{ml}$ TCDD & 22 & 59 & 41 & 0 & Pictured in Figure 5 \\
\hline & \multirow[t]{2}{*}{6} & $0.1 \%$ DMSO & 28 & 0 & 4 & 96 & \\
\hline & & $10 \mathrm{ng} / \mathrm{ml} \mathrm{TCDD}$ & 28 & 100 & 0 & 0 & \\
\hline & \multirow[t]{2}{*}{7} & $0.1 \%$ DMSO & 20 & 0 & 0 & 100 & \\
\hline & & $10 \mathrm{ng} / \mathrm{ml}$ TCDD & 20 & 30 & 70 & 0 & \\
\hline & \multirow[t]{2}{*}{8} & $0.1 \%$ DMSO & 25 & 0 & 16 & 84 & \\
\hline & & $10 \mathrm{ng} / \mathrm{ml} \mathrm{TCDD}$ & 30 & 90 & 10 & 0 & \\
\hline \multirow[t]{2}{*}{ ahr1a $a^{\text {uab139/- }} ;$ ahr1b uab141-/-,-/+,+/+ } & \multirow[t]{2}{*}{$9^{*}$} & $0.1 \%$ DMSO & 24 & 0 & 0 & 100 & $\begin{array}{l}n=24 \text { genotyped, } n=3 \\
\quad \text { ahr1 } a^{\text {uab139/-}} ; \text { ahr1 } b^{\text {uab141/-}} ; \\
n=5 \text { ahr1 }\end{array}$ \\
\hline & & $10 \mathrm{ng} / \mathrm{ml} \mathrm{TCDD}$ & 24 & 100 & 0 & 0 & 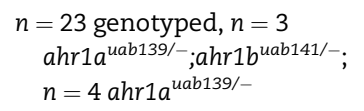 \\
\hline \multirow[t]{2}{*}{ ahr1a $a^{\text {uab139/- }} ;$ ahr1b $b^{\text {uab141-/-,-/+,+/+ }}$} & \multirow[t]{2}{*}{$10^{*}$} & $0.1 \%$ DMSO & 36 & 0 & 3 & 100 & $\begin{array}{l}n=24 \text { genotyped, } n=3 \\
\quad \text { ahr1 } a^{\text {uab139/-}} ; \text { ahr1 } b^{\text {uab141/- }} ; \\
\quad n=5 \text { ahr1 }^{\text {uab139/- }}\end{array}$ \\
\hline & & $10 \mathrm{ng} / \mathrm{ml} \mathrm{TCDD}$ & 36 & 97 & 3 & 0 & $\begin{array}{l}n=23 \text { genotyped, } n=3 \\
\quad \text { ahr1 } a^{\text {uab139/-}} ; \text { ahr1b } b^{\text {uab141/- }} ; \\
\quad n=4 \text { ahr1a }^{\text {uab139/- }}\end{array}$ \\
\hline \multirow[t]{2}{*}{ ahr1a $a^{\text {uab139/- }} ;$ ahr1b ${ }^{\text {uab141-/-,-/+,+/+ }}$} & \multirow[t]{2}{*}{$11^{*}$} & $0.1 \%$ DMSO & 15 & 0 & 0 & 97 & 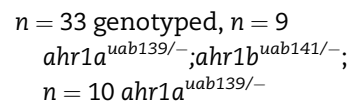 \\
\hline & & $10 \mathrm{ng} / \mathrm{ml} \mathrm{TCDD}$ & 16 & 100 & 0 & 0 & $\begin{array}{l}n=34 \text { genotyped, } n=9 \\
\quad \text { ahr1a } a^{\text {uab139/- }} ; \text { ahr } 1 b^{\text {uab141/- }} ; n \\
\quad=10 \text { ahr1 }\end{array}$ \\
\hline ahr ${ }^{\text {uab147-/-,-/+,+/+ }}$ & $1^{*}$ & $0.1 \%$ DMSO & 20 & 0 & 10 & 90 & $\begin{array}{l}\text { Pictured in Figure 5, } n=12 \\
\text { genotyped, } n=4 \\
\text { ahr2 }{ }^{\text {uab147/- }}\end{array}$ \\
\hline & & $10 \mathrm{ng} / \mathrm{ml} \mathrm{TCDD}$ & 20 & 65 & 15 & 20 & $\begin{array}{l}\text { Pictured in Figure 5, } n=12 \\
\text { genotyped, } n=4 \\
\text { ahr } 2^{\text {uab147/- }}\end{array}$ \\
\hline
\end{tabular}


Table 4. (continued)

\begin{tabular}{|c|c|c|c|c|c|c|c|}
\hline Genotype & Clutch & Treatment & $n$ & $\%$ PCE, $3 \mathrm{dpf}$ & $\begin{array}{l}\text { \%Mortality, } \\
3 \text { dpf }\end{array}$ & $\begin{array}{l}\text { \%Normal, } \\
3 \mathrm{dpf}\end{array}$ & Notes \\
\hline & \multirow[t]{2}{*}{$2^{*}$} & $0.1 \%$ DMSO & 31 & 0 & 0 & 100 & $\begin{array}{l}n=24 \text { genotyped, } n=4 \\
\quad \text { ahr } 2^{\text {uab147/- }}\end{array}$ \\
\hline & & $10 \mathrm{ng} / \mathrm{ml} \mathrm{TCDD}$ & 39 & 79 & 0 & 21 & $\begin{array}{l}n=24 \text { genotyped, } n=6 \\
\quad \text { ahr } 2^{\text {uab147/- }}\end{array}$ \\
\hline & \multirow[t]{2}{*}{$3^{*}$} & $0.1 \%$ DMSO & 50 & 2 & 4 & 94 & $\begin{array}{l}n=24 \text { genotyped, } n=4 \\
\quad \text { ahr2 } 2^{\text {uab147/- }}\end{array}$ \\
\hline & & $10 \mathrm{ng} / \mathrm{ml} \mathrm{TCDD}$ & 50 & 72 & 0 & 28 & $\begin{array}{l}n=24 \text { genotyped, } n=11 \\
\quad \text { ahr } 2^{\text {uab147/- }}\end{array}$ \\
\hline & \multirow[t]{2}{*}{$4^{*}$} & $0.1 \%$ DMSO & 43 & 0 & 5 & 95 & $\begin{array}{l}n=40 \text { genotyped, } n=6 \\
\quad \text { ahr } 2^{\text {uab147/ }-}\end{array}$ \\
\hline & & $10 \mathrm{ng} / \mathrm{ml} \mathrm{TCDD}$ & 44 & 66 & 2 & 32 & $\begin{array}{l}n=41 \text { genotyped, } n=14 \\
\quad \text { ahr } 2^{\text {uab147/- }}\end{array}$ \\
\hline & \multirow[t]{2}{*}{$5^{*}$} & $0.1 \%$ DMSO & 45 & 2 & 2 & 96 & $\begin{array}{l}n=40 \text { genotyped, } n= \\
\quad 8 \text { ahr } 2^{\text {uab147/- }}\end{array}$ \\
\hline & & $10 \mathrm{ng} / \mathrm{ml} \mathrm{TCDD}$ & 48 & 67 & 0 & 33 & $\begin{array}{l}n=40 \text { genotyped, } n=16 \\
\quad a h r 2^{\text {uab147/- }}\end{array}$ \\
\hline \multirow[t]{8}{*}{ MZesr1 ${ }^{\text {uab119/- }}$} & \multirow[t]{2}{*}{1} & $0.1 \%$ DMSO & 20 & 0 & 10 & 90 & \\
\hline & & $10 \mathrm{ng} / \mathrm{ml} \mathrm{TCDD}$ & 20 & 90 & 10 & 0 & \\
\hline & \multirow[t]{2}{*}{2} & $0.1 \%$ DMSO & 11 & 0 & 9 & 91 & \\
\hline & & $10 \mathrm{ng} / \mathrm{ml} \mathrm{TCDD}$ & 11 & 82 & 18 & 0 & \\
\hline & \multirow[t]{2}{*}{3} & $0.1 \%$ DMSO & 25 & 0 & 0 & 100 & Pictured in Figure 6 \\
\hline & & $10 \mathrm{ng} / \mathrm{ml} \mathrm{TCDD}$ & 25 & 100 & 0 & 0 & Pictured in Figure 6 \\
\hline & \multirow[t]{2}{*}{4} & $0.1 \%$ DMSO & 25 & 0 & 0 & 100 & \\
\hline & & $10 \mathrm{ng} / \mathrm{ml} \mathrm{TCDD}$ & 25 & 76 & 24 & 0 & \\
\hline \multirow[t]{6}{*}{ MZesr2a $a^{\text {uab134/- }}$} & \multirow[t]{2}{*}{1} & $0.1 \%$ DMSO & 18 & 0 & 11 & 89 & \\
\hline & & $10 \mathrm{ng} / \mathrm{ml} \mathrm{TCDD}$ & 18 & 100 & 0 & 0 & \\
\hline & \multirow[t]{2}{*}{2} & $0.1 \%$ DMSO & 8 & 0 & 13 & 88 & \\
\hline & & $10 \mathrm{ng} / \mathrm{ml} \mathrm{TCDD}$ & 8 & 63 & 38 & 0 & \\
\hline & \multirow[t]{2}{*}{3} & $0.1 \%$ DMSO & 13 & 0 & 15 & 85 & Pictured in Figure 6 \\
\hline & & $10 \mathrm{ng} / \mathrm{ml} \mathrm{TCDD}$ & 14 & 93 & 7 & 0 & Pictured in Figure 6 \\
\hline \multirow[t]{10}{*}{ esr2b uab127-/-,-/+,+/+ } & \multirow[t]{2}{*}{$1^{*}$} & $0.1 \%$ DMSO & 25 & 4 & 0 & 96 & $\begin{array}{l}\text { Pictured in Figure } 6, n=12 \\
\text { genotyped, } n=4 \\
\text { esr } 2 b^{\text {uab127/- }}\end{array}$ \\
\hline & & $10 \mathrm{ng} / \mathrm{ml} \mathrm{TCDD}$ & 25 & 100 & 0 & 0 & $\begin{array}{l}\text { Pictured in Figure } 6, n=12 \\
\text { genotyped, } n=3 \\
\text { esr } 2 b^{\text {uab127/- }}\end{array}$ \\
\hline & \multirow[t]{2}{*}{$2^{*}$} & $0.1 \%$ DMSO & 25 & 0 & 0 & 100 & $\begin{array}{l}25 \% \text { presumed homozygotes } \\
\text { (not genotyped) }\end{array}$ \\
\hline & & $10 \mathrm{ng} / \mathrm{ml} \mathrm{TCDD}$ & 25 & 100 & 0 & 0 & \\
\hline & \multirow[t]{2}{*}{$3^{*}$} & $0.1 \%$ DMSO & 24 & 0 & 0 & 100 & $\begin{array}{l}25 \% \text { presumed homozygotes } \\
\text { (not genotyped) }\end{array}$ \\
\hline & & $10 \mathrm{ng} / \mathrm{ml} \mathrm{TCDD}$ & 25 & 100 & 0 & 0 & \\
\hline & \multirow[t]{2}{*}{$4^{*}$} & $0.1 \%$ DMSO & 25 & 0 & 0 & 100 & $\begin{array}{l}25 \% \text { presumed homozygotes } \\
\text { (not genotyped) }\end{array}$ \\
\hline & & $10 \mathrm{ng} / \mathrm{ml}$ TCDD & 25 & 100 & 0 & 0 & \\
\hline & \multirow[t]{2}{*}{$5^{*}$} & $0.1 \%$ DMSO & 25 & 4 & 0 & 96 & $\begin{array}{l}25 \% \text { presumed homozygotes } \\
\text { (not genotyped) }\end{array}$ \\
\hline & & $10 \mathrm{ng} / \mathrm{ml} \mathrm{TCDD}$ & 25 & 100 & 0 & 0 & \\
\hline \multirow[t]{8}{*}{ MZgper ${ }^{\text {uab102/- }}$} & \multirow[t]{2}{*}{1} & $0.1 \%$ DMSO & 25 & 16 & 12 & 72 & Pictured in Figure 6 \\
\hline & & $10 \mathrm{ng} / \mathrm{ml} \mathrm{TCDD}$ & 25 & 68 & 32 & 0 & Pictured in Figure 6 \\
\hline & \multirow[t]{2}{*}{2} & $0.1 \%$ DMSO & 22 & 5 & 0 & 95 & \\
\hline & & $10 \mathrm{ng} / \mathrm{ml} \mathrm{TCDD}$ & 20 & 95 & 5 & 0 & \\
\hline & \multirow[t]{2}{*}{3} & $0.1 \%$ DMSO & 25 & 0 & 4 & 96 & \\
\hline & & $10 \mathrm{ng} / \mathrm{ml} \mathrm{TCDD}$ & 25 & 96 & 4 & 0 & \\
\hline & \multirow[t]{2}{*}{4} & $0.1 \%$ DMSO & 25 & 0 & 4 & 96 & \\
\hline & & $10 \mathrm{ng} / \mathrm{ml} \mathrm{TCDD}$ & 25 & 84 & 16 & 0 & \\
\hline
\end{tabular}

Embryos are grouped by genotype and clutch, with each clutch of embryos split between 2 treatment groups: $0.1 \%$ DMSO (vehicle) or $10 \mathrm{ng} / \mathrm{ml}$ TCDD. An additional 2 treatment groups are present for pharmacologic inhibition of estrogen receptors in wild-type embryos (10 $\mu \mathrm{M} \mathrm{ICI182,} 780$ and $10 \mu \mathrm{M}$ ICI182, $780+10 \mathrm{ng} / \mathrm{ml} \mathrm{TCDD})$. Asterisk (*) denotes clutches derived from heterozygous parents and thus containing homozygous, heterozygous and wild-type siblings. All genotypes included in the clutch are listed in the "Genotype" column. The number of embryos genotyped and number of homozygous embryos is listed in the "Notes" column. Mutant embryos derived from homozygous parents are denoted MZ. The percent of embryos with pericardial edema (PCE), percent mortality, and percent normal embryos at 3 dpf are listed in right 3 columns. All TCDD-treated groups had 0\% normal embryos at $3 \mathrm{dpf}$, except for mixed-genotype ahr 2 mutant clutches. TCDD-exposed embryos with no

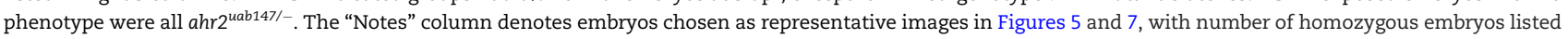
for mixed genotype clutches. 

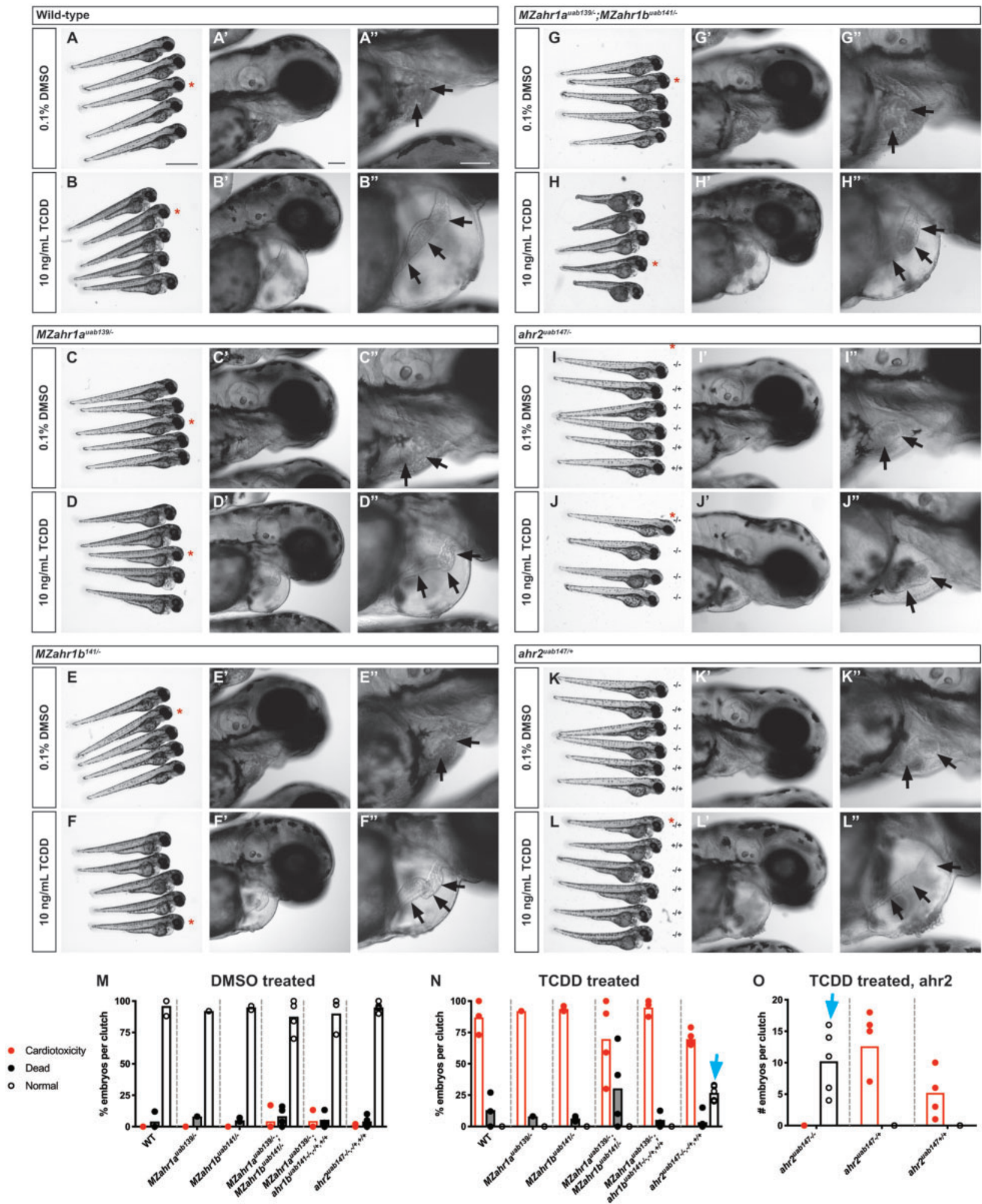

Figure 5. TCDD causes cardiotoxicity in ahr1 mutants but not in ahr2 mutants. A-L, Representative images of embryos at 3 days post fertilization (dpf) exposed to DMSO or TCDD. Embryos derived from heterozygous parents are denoted as maternal zygotic. Images in panels A-L display overview images of treated embryos and asterisks denote embryos detailed in panels $\mathrm{A}^{\prime}-\mathrm{L}^{\prime}$ and $\mathrm{A}^{\prime \prime}-\mathrm{L}^{\prime \prime}$. Black arrows in panels $\mathrm{A}^{\prime \prime}-\mathrm{L}^{\prime \prime}$ point to the heart within the pericardial cavity. Obvious pericardial edema and failure of heart looping is present in $100 \%$ of embryos from all TCDD-treated groups with the exception of ahr2 -/- mutants (J, $\left.J^{\prime}, J^{\prime \prime}\right)$, in which $0 \%$ of embryos displayed cardiotoxicity. Scale bar in panel $A=1000 \mu \mathrm{m}$ and applies to panels B-L. Scale bars in panels $\mathrm{A}^{\prime}$ and $\mathrm{A}^{\prime \prime}=100 \mu \mathrm{m}$ and apply to $\mathrm{B}^{\prime}-\mathrm{L}^{\prime}$ and $\mathrm{B}^{\prime \prime}-\mathrm{L}^{\prime \prime}$, respectively. M and N, Quantitation of percent of embryos from each clutch (1-5 clutches per genotype or mixed genotype group, 14-50 embryos/treatment) demonstrating cardiotoxicity (filled dots/open bars), mortality (black dots/gray filled bars), or normal development (white dots/white open bars) at 3 dpf. Genotypes are separated by vertical gray dotted lines in each graph. Each dot represents the percent of embryos from a single clutch and bars represent the mean for each genotype. A number of homozygous embryos from mixed clutch groups are listed in Table 4. Arrow in (N) denotes normal TCDD-treated embryos in ahr2 mixed clutches. Normal embryos were not observed in any other TCDD-treated group. O, Number of embryos from each clutch of surviving ahr ${ }^{147}$ TCDD-treated embryos from (N) demonstrating cardiotoxicity (filled dots/open bars) or normal development (white dots/white open bars). Each dot represents the number of embryos from a single clutch. All normal TCDD-treated embryos in ahr2 mixed clutch are ahr2 -/- (arrow), whereas all heterozygous and wild-type siblings demonstrate cardiotoxicity. Legend applies to M-O. 
A Treatment groups and exposure paradigm

\begin{tabular}{lcc} 
& Treatment 1 & Treatment 2 \\
\cline { 2 - 2 } Control 1: & DMSO & DMSO \\
Control 2: & TCDD & DMSO \\
Control 3: & DMSO & 7 -ER \\
Experimental: & TCDD & $7-E R$
\end{tabular}
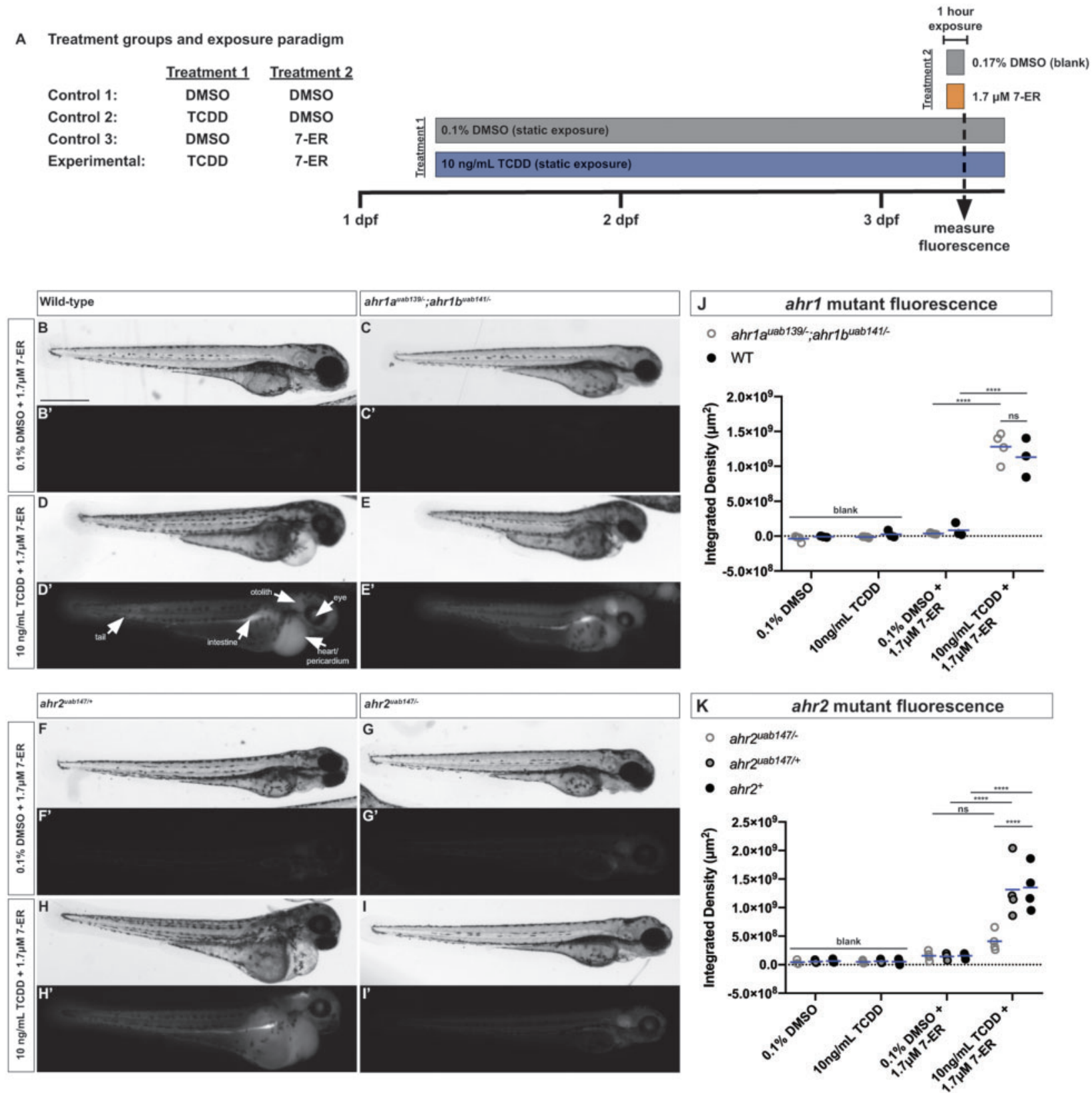

Figure 6. CYP1 activity is significantly reduced in ahr2, but not ahr1, mutant embryos following TCDD exposure. A, Graphic demonstrating treatment groups and exposure paradigm for CYP1 activity assay. Embryos from each clutch were divided into 4 groups ( 3 controls and 1 experimental). Treatment 1 indicates static exposure to $0.1 \%$ DMSO (top horizontal bar) or $10 \mathrm{ng} / \mathrm{ml}$ TCDD (bottom bar) from 1 to $3 \mathrm{dpf}$. Treatment 2 indicates $1 \mathrm{~h}$ exposure to $0.17 \%$ DMSO (blank) or $1.7 \mu \mathrm{M}$ 7-ER. Fluorescence of resorufin (metabolite of 7-ER) was measured following $1 \mathrm{~h}$ exposure to treatment 2. B-I, Representative images of wild-type and ahr2 or ahr1 mutant embryos. ahr2 mutant embryos and siblings are on the fluorescent tg(gata1:DsRed;fli1:GFP) background. ahr1 mutant embryos and wild-type embryos for comparison are on a nontransgenic background. Brightfield (B-I) and fluorescent $\left(\mathrm{B}^{\prime}-\mathrm{I}^{\prime}\right)$ images for 7-ER-treated embryos (control 3 and experimental groups) shown. White arrows in panel $\mathrm{D}^{\prime}$ indicate areas of fluorescence in wild-type TCDD+7-ER-treated embryos. Fluorescence is obvious in wild-type and ahr1 mutant embryos, but largely absent in ahr2 mutant embryos. J and K, Quantification of fluorescence in wild-type and ahr mutant embryos. Each dot represents the mean fluorescence of embryos from a single clutch (3-5 clutches per genotype, 2-20 embryos per clutch for each genotype and treatment group). Horizontal line represents the mean of all clutches. ahr 2 -/- embryos have significantly reduced fluorescence compared with heterozygous and wild-type siblings following TCDD exposure. Fluorescence is significantly increased in DMSO+7-ER versus TCDD+7-ER-treated $a h r 2-/+$ and +/+ embryos, but not in ahr $-/-$ embryos. No change in fluorescence is observed between ahr1a; ahr1b -/- and wild-type embryos following TCDD+7-ER exposure, and both genotypes demonstrate significantly increased fluorescence compared with DMSO+7-ER-exposed embryos. ${ }^{* * * *} p<.0001$, ns, not significant ( $p>$.05), 2-way ANOVA with Tukey's multiple comparisons test. Scale bar in $\mathrm{A}=50 \mu \mathrm{m}$ and applies to A-H, $\mathrm{A}^{\prime}-\mathrm{H}^{\prime}$. Abbreviations: TCDD, 2,3,7,8-tetrachlorodibenzo-p-dioxin; 7-ER, 7-ethoxyresorufin; dpf, days post fertilization.

difference $=1.20 \mathrm{e} 9, p<.0001 ;$ 2-way ANOVA). Similarly, ahr1 mutant and non-transgenic wild-type embryos had significantly increased fluorescence in TCDD versus DMSO-treated embryos exposed to 7-ER (Figure 6J; DMSO+7-ER: ahr1a $a^{\text {uab139/- }}$; ahr1buab141/- $=3.63 \mathrm{e} 7 \pm 1.02 \mathrm{e} 7 \mu \mathrm{m}^{2}$, mean difference $=1.25 \mathrm{e} 9, p<.0001 ; \mathrm{WT}=8.42 \mathrm{e} 7 \pm 9.51 \mathrm{e} 7 \mu \mathrm{m}^{2}$, mean difference $=1.05 \mathrm{e} 9, p<.0001 ; 2$-way ANOVA). Limited background fluorescence was observed in the absence of TCDD and/or 7-ER 
(Figs. 6J and K). These results provide functional evidence to further support the conclusion that Ahr2 mediates the effects of TCDD exposure in zebrafish embryos and that Ahr1a and Ahr1b are not required for TCDD toxicity.

\section{Estrogen Receptors Are Not Required for TCDD-induced Cardiotoxicity in Embryos}

Aryl hydrocarbon receptor is a ligand-dependent transcription factor that partners with the ARNT along with other cofactors at dioxin response elements in the DNA to mediate changes in gene transcription (Burbach et al., 1992; Reyes et al., 1992). Estrogen receptors alpha and beta have been shown to directly interact with AHR in vitro and in vivo to regulate gene expression (Beischlag and Perdew, 2005; Ohtake et al., 2003, 2007), yet it is unclear whether this interaction is constitutive or conditional. To test the hypothesis that ERs are recruited by AHR2 following TCDD treatment, we exposed zebrafish with mutations in each of the nuclear estrogen receptors esr1 (ER $\alpha$ ), esr2a (ER $\beta 1)$, and esr $2 b$ (ER $\beta 2)$ to TCDD. If ERs are required for TCDD toxicity, then ER mutant embryos should be resistant to TCDD toxicity, similar to ahr2 mutant embryos. We found, however, that $100 \%$ of ER mutant embryos (3-5 clutches per genotype, 3-25 embryos per clutch) displayed abnormal PCE and heart looping at $3 \mathrm{dpf}$ following TCDD treatment (Table 4, Figs. 7A-H and P).

It is possible that there is a compensatory relationship among Esr1, Esr2a, and Esr2b as cofactors for Ahr2 (eg esr2b is upregulated in esr1 mutants to mediate the effects of TCDD). To test this hypothesis, we treated embryos with TCDD together with the pan-nuclear estrogen receptor antagonist, ICI-182, 780 (Fulvestrant). We saw that pharmacological inhibition of ERs did not protect embryos from TCDD toxicity, as $100 \%$ of cotreated embryos (3 clutches, 15 embryos per clutch) demonstrated PCE and abnormal heart looping or mortality at $3 \mathrm{dpf}$ (Table 4, Figs. 7K-N and Q). To further investigate the hypothesis that estrogen receptors are required for ahr2 activity, we tested whether the G protein-coupled estrogen receptor (gper) is required for TCDD toxicity. In agreement with results from nuclear ERs, $100 \%$ of gper mutants (4 clutches, $20-25$ embryos per clutch) demonstrated characteristic TCDD toxicity or mortality at $3 \mathrm{dpf}$ (Table 4, Figs. 7I and J). Less than 14\% mortality is observed in all DMSO- or ICI-182, 780-treated embryos from the same clutches and $\leq 16 \%$ of embryos demonstrate PCE or abnormal heart looping at $3 \mathrm{dpf}$ (Table 4, Figure 70), providing evidence that observed cardiotoxicity is specific to TCDD treatment and not a side effect of mutation or ICI182, 780 treatment. These results suggest that ERs are not required for TCDD toxicity, and that estrogen receptors are not required cofactors for Ahr2.

\section{DISCUSSION}

We find that ahr2 regulates TCDD-toxicity and fin and craniofacial morphology in zebrafish, consistent with previous results (Garcia et al., 2018; Goodale et al., 2012; Prasch et al., 2003). Using new ahr1 mutants, we demonstrate that these functions of ahr2 are independent of ahr1 genes. Furthermore, we provide evidence that Ahr2 recruits cofactors in a context-dependent manner.

The fin deformities observed in adult ahr $2^{\text {uab147/- }}$ mutants were severe, resulting in dysmorphic caudal and pectoral fins and absent anal fins in adult zebrafish of both sexes (Figure 2). This defect first presents in juvenile stages of growth, as mutant larvae have normal fins at $5 \mathrm{dpf}$ (Figure 4). Previous studies reported abnormal morphology in adult fins of ahr2 mutant fish (Garcia et al., 2018; Goodale et al., 2012), resulting in a "damaged fin" phenotype. However, in our mutant we observe almost complete absence of anal fins, more akin to the zebrafish mutant finless (Haffter et al., 1996; van Eeden et al., 1996). This mutant was later discovered to harbor a mutation in the edar gene encoding the ectodysplasin A receptor (Harris et al., 2008). Similar to ahr $2^{\text {uab147/- }}$ mutants, edar homozygous mutants demonstrate normal larval fin development, but have an absence of all fins (pectoral, anal, caudal, pelvic, and dorsal) in adulthood. edar mutants first demonstrate fin defects in juvenile metamorphosis and adulthood. One hypothesis is that Ahr2 is involved in Edar signaling to regulate fin development. This is supported by the fact that the ectodysplasin A receptor and its ligand ectodysplasin are structurally analogous to tumor necrosis factor receptor, and its ligand, tumor necrosis factor alpha, a regulator of inflammation. Aryl hydrocarbon receptor has been shown to regulate inflammation in a ligand-dependent manner (Quintana et al., 2008). Furthermore, Ahr null mice have altered populations of immune cells (Fernandez-Salguero et al., 1995; Singh et al., 2011). It is possible that an endogenous ligand for Ahr2 activates the Edar pathway in zebrafish, leading to disrupted fin formation in ahr 2 mutant fish. More investigation is required to determine at what stage and by what mechanism Ahr2 is involved in fin morphology and immune system function.

ahr2 mutant larvae had grossly normal craniofacial structure whereas adults displayed craniofacial abnormalities. Previous studies using $\mu \mathrm{CT}$ imaging of ahr2 mutant adult zebrafish reported abnormal skull morphology of several bones of the neurocranium, including the opercular bones, although phenotypic differences were not quantitated (Garcia et al., 2018; Goodale et al., 2012). In our analysis of ahr mutant skulls using $\mu \mathrm{CT}$, we observed a narrowing of the ventral and frontal skull by ratio of the width between opercular and dentate bones exclusively in ahr2 mutants. This narrowed ventral/frontal skull shape in ahr2 mutants is suggestive of disrupted skull patterning. Previous studies identified genes and pathways important for embryonic craniofacial development (Kimmel et al., 2003, 2007). However, the processes governing juvenile and adult craniofacial morphology are less well understood (Fisher et al., 2003; Parsons et al., 2011). Dermal skeletal development in zebrafish occurs during juvenile morphogenesis and adulthood to form structures including the lateral opercular bones, fin rays, and scales (Sire and Huysseune, 2003). The observation of severely deformed fins coupled with disproportionate ventral skull width in ahr2 mutants suggests that Ahr2 may play a role in postembryonic dermal skull development in zebrafish. In a study screening for mutants that affect postembryonic zebrafish development, 1 mutation classified as "broadly affecting the dermal skeleton" ( $d m h 3$ mutant) was identified as a missense mutation in the edar receptor (Henke et al., 2017). This receptor severely disrupts fin growth, as described above, and was also shown to affect scale formation. Although skull morphology was not reported for this mutant, it is possible that the skull defect observed in ahr2 mutants is related to the edar pathway. Further work is required to support or reject this hypothesis, including analysis of scale development and morphology in adult ahr2 mutants. In addition, future work should determine the precise developmental stage at which fin and skull defects first appear.

The increased severity of fin defects in our mutant compared with previously published mutants and reduced severity of abnormal craniofacial morphology in our mutant compared 

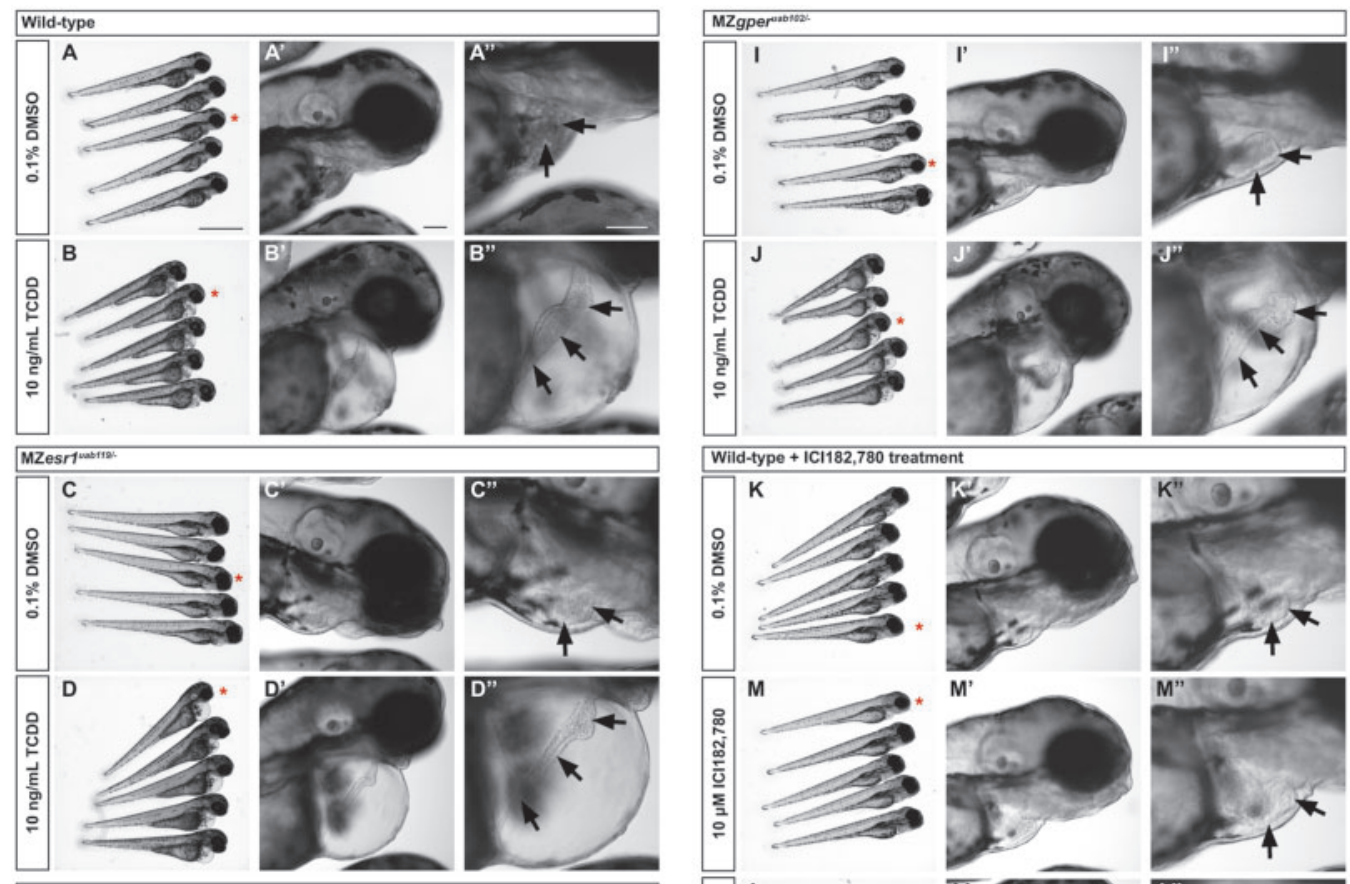

\section{Wild-type + ICI182,780 treatment}
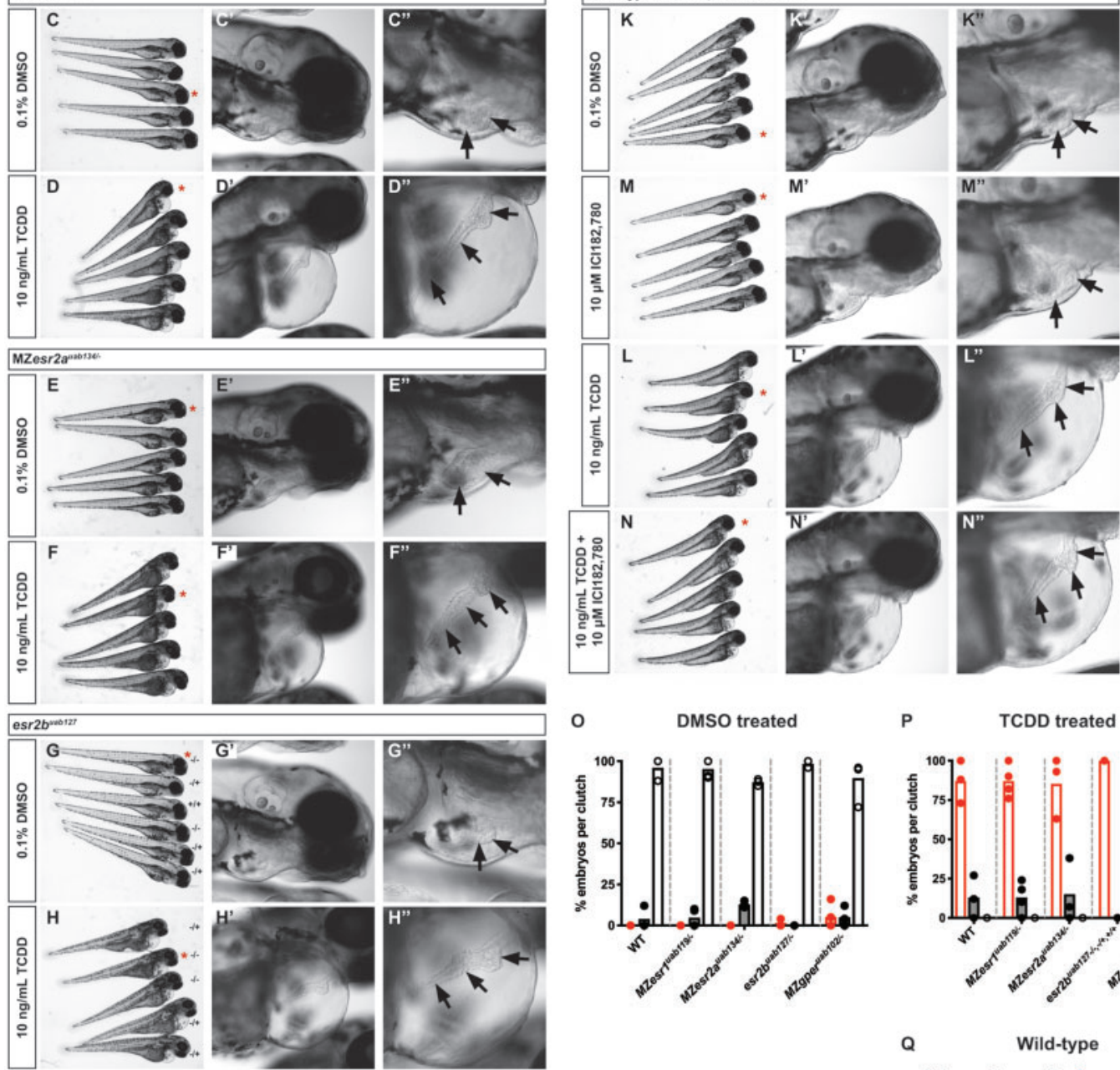

$\mathbf{P}$
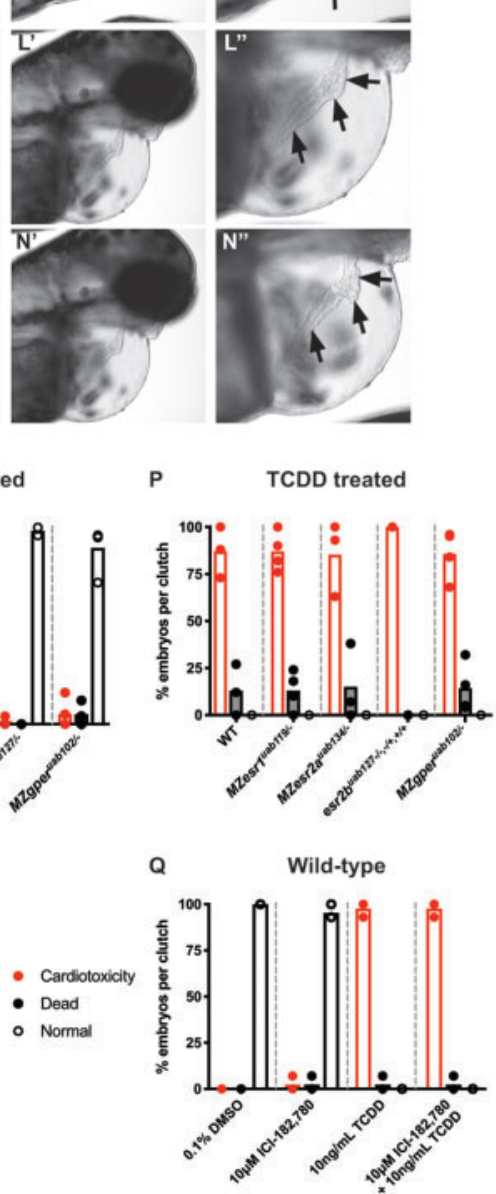

Figure 7. Estrogen receptors are not required for TCDD cardiotoxicity. A-N, Embryos of the indicated genotype were exposed to DMSO, TCDD, or the estrogen receptor antagonist ICI182, 780 at 3 days post fertilization (dpf). esr2b mutant embryos were derived from heterozygous parents, thus the clutch contained a mix of wild-type and mutant embryos (denoted as wild type $+/+$, heterozygous $-/+$, or homozygous $-/-$, panels $\mathrm{G}$ and $\mathrm{H}, \mathrm{P}$ ). Other mutant embryos were derived from homozygous parents and are denoted as maternal zygotic. Images in panels $\mathrm{A}-\mathrm{N}$ display overview images of treated embryos and asterisks denote embryos detailed in panels $\mathrm{A}^{\prime}-\mathrm{N}^{\prime}$ and $\mathrm{A}^{\prime \prime}-\mathrm{N}^{\prime \prime}$. Black arrows in panels $\mathrm{A}^{\prime \prime}-\mathrm{N}^{\prime \prime}$ point to the heart within the pericardial cavity. Pericardial edema and failure of heart looping are present in $100 \%$ of embryos from all TCDD-treated groups. Scale bar in panel $\mathrm{A}=1 \mathrm{~mm}$ and applies to panels B-N. Scale bars in panels $\mathrm{A}^{\prime}$ and $\mathrm{A}^{\prime \prime}=100 \mu \mathrm{m}$ and apply to $\mathrm{B}^{\prime}-\mathrm{N}^{\prime}$ and $\mathrm{B}^{\prime \prime}-\mathrm{N}^{\prime \prime}$, respectively. Wild-type embryos in panels A and B are the same embryos shown in Figures 5A and 5B. O-Q Quantitation of percent of embryos from each clutch (3-25 embryos/treatment) demonstrating cardiotoxicity (filled dots/open bars), mortality (black dots/gray filled bars), or normal development (white dots/white open bars) at 3 dpf. Genotypes or treatment groups are separated by vertical gray dotted lines in each graph. Each dot represents the percent of embryos from a single clutch (3-5 clutches per genotype or treatment group) and bars represent the mean for each group. Legend applies to O-Q. 
with previously published mutants could be explained by 3 possibilities. First, all published ahr2 mutant zebrafish could be hypomorphic rather than complete null alleles. Because osu1 and uab147 alleles are in different locations in the ahr2 open reading frame, it is possible that each allele reduces, but does not eliminate, Ahr2 function differently. Second, nonspecific mutations present in the genome could influence the severity of fin and craniofacial phenotypes. For example, the hu3335 allele was generated using the TILLING approach, and background mutations are a known side-effect of this approach. The presence of background mutations in the ahr $2^{\text {uab147/- }}$ line is unlikely, as heterozygotes were crossed to wild type for at least 3 generations before heterozygotes were crossed to each other to generate homozygous embryos. Third, it is possible that strain differences account for phenotypic differences between mutants, as has been suggested previously by genetic comparisons between zebrafish strains (Balik-Meisner et al., 2018). $a h r 2^{\text {hu3335 }}$ and ahr $2^{\text {osu1 }}$ mutants were generated on the 5D wildtype strain (Garcia et al., 2018; Goodale et al., 2012), whereas ahr ${ }^{\text {uab147 }}$ mutants were generated on the AB wild-type strain. It is likely that strain differences variably affect fin and craniofacial morphology-eg, fin defects are more severe in AB-strain ahr2 mutants, whereas craniofacial defects are more severe in $5 \mathrm{D}$-strain $a h r 2$ mutants. Although the same primary structures are affected in ahr2 mutants on $A B$ and $5 D$ strains, strainspecific differences may increase phenotype severity for fin formation and reduce operculum dysmorphia in the ahr $2^{\text {uab147 }} \mathrm{mu}$ tant. Regardless of the differences in severity of fin and craniofacial phenotypes between different ahr 2 mutants, this study provides evidence that Ahr2 regulates fin and skull maturation and/or maintenance independently of Ahr1 receptors.

Though this study and previous work demonstrate roles for Ahr2 in fin and craniofacial development, less is known about the function of Ahr1a and Ahr1b in zebrafish. Furthermore, ligands with the ability to activate Ahr1a or Ahr1b in vivo have not been characterized. A recent study evaluated the function of $a h r$ genes in vascular development in zebrafish embryos using an ahr1a single mutant, a double ahr1b/ahr2 mutant and a triple ahr1a;ahr1b;ahr2 mutant (Sugden et al., 2017). All mutants were grossly normal during development up to $5 \mathrm{dpf}$, consistent with normal morphology in our mutant embryos. When comparing endogenous and $\beta \mathrm{NF}$-induced expression of the AHR target gene CYP1A1, they found that ahr1a mutants had normal expression patterns of CYP1A1, whereas ahr1b/ahr2 and ahr1a;ahr1b;ahr2 mutants lost both endogenous and $\beta$ NF-induced CYP1A1 expression. This is in contrast to ahr2 single mutants, which retained partial endogenous and $\beta$ NF-induced CYP1A1 expression. These results support the theory that Ahr1b, but not Ahr1a, is an active AHR paralog. It is possible, however, that Ahr1a may activate other target genes that were not studied. Furthermore, no toxicity or abnormal morphology was reported with $\beta$ NF treatment in wild-type embryos or in $a h r$ mutant embryos. Therefore, the biological relevance of Ahr1bspecific CYP1A1 activation is unclear. Other studies using morpholino knockdown of ahr genes have shown that Ahr1a, but not Ahr1b, contributes to the toxicity of PAHs and PCB-126 (Garner et al., 2013; Incardona et al., 2006). Evidence from in silico molecular docking studies suggests that another AHR ligand, leflunomide, is capable of binding each of the zebrafish AHRs with comparable binding affinities (Goodale et al., 2012; O'Donnell et al., 2010). Further evidence in leflunomide-treated embryos suggests that Ahr1a induces expression of CYP1A1 in the liver in the absence of both Ahr1b and Ahr2. Combined with our results that Ahr1a and Ahr1b are not required for TCDD- dependent toxicity in embryos, these results suggest that zebrafish ahr1 receptors are not required for canonical AHR signaling, but may have ligand- and tissue-specific effects outside of TCDD-mediated toxicity.

The increase in CYP1 activity in ahr1a;ahr1b double mutant embryos following TCDD exposure suggests that neither Ahr1a nor Ahr1b are required for TCDD-mediated CYP1 activity in zebrafish embryos. Wild-type and ahr1a uab139/-;ahr1buab141/double mutant embryos exhibited similar increases in CYP1 activity following TCDD exposure. In contrast, CYP1 activity in ahr $2^{\text {uab147/- }}$ embryos was not significantly increased following TCDD exposure. It is possible that because we measured whole embryo fluorescence, we missed tissue-specific decreases in CYP1 expression due to loss of $a h r 1 b$ in $a h r 1 a$;ahrlb double mutants. However, because there was not a decrease in CYP1 activity in ahr1a;ahr1b double mutants, this is unlikely. In addition, it is possible that $a h r 2$ is upregulated in $a h r 1 a$;ahr1b double mutants to compensate for loss of ahr1 genes. In this case, this still provides evidence that $a h r 2$ is the predominant Ah receptor in zebrafish, as ahr2, but not ahr1 receptors, can compensate for loss of the complementary AHR paralog(s). Overall, these results support the conclusion that ahr1 receptors are nonfunctional AHR paralogs or act via noncanonical or non-conserved AHR signaling pathways.

Though the previously cited studies, and this study, suggest $a h r$ genes are not essential for embryonic or larval development, this study is the first to characterize the effect of ahr1a and $a h r 1 b$ mutation on adult morphology. In contrast to ahr2 mutants, which display dysmorphic fins and skulls in adulthood, ahr1 single and double mutants are morphologically normal. This suggests that ahr2 is the primary zebrafish AHR paralog regulating both endogenous and environmentally induced AHR activity. We cannot rule out, however, that less obvious phenotypes are present in ahr1 mutants that affect normal physiology or susceptibility to environmental stress. In addition, it should be noted that it is possible that the lack of phenotypes in ahr1 mutants are due to hypomorphic alleles. The ahr1a $a^{\text {uab139 }}$ mutation is in the transactivation domain of the protein. Therefore, it is possible that a truncated protein with intact DNA and ligand-binding domains is produced. However, it is unlikely that such a truncated protein would be functional. Wild-type ahr1a fails to bind TCDD or activate XRE-dependent transcription in vitro (Andreasen, Hahn, et al., 2002). Evidence from previously published ahr1a mutant zebrafish (mu153 allele) suggests that ahr1a does not regulate CYP1A1 expression in vivo (Sugden et al., 2017), consistent with our results using the uab139 allele. We would therefore not expect a truncated Ahr1a protein to mediate the effects of TCDD toxicity. We cannot exclude the possibility that a truncated Ahr1a variant causes a gain-of-function. It is possible that the amino acids deleted in the uab139 allele (accounting for $50 \%$ of the total residues) serve to repress a dominant function of the bHLH, PAS-A, and LBDs, although this seems unlikely.

In addition to investigating the function of Ahr1a and Ahr1b in toxicity and development, we also investigated AHR/ER crosstalk in zebrafish embryos. Aryl hydrocarbon receptor has been shown to regulate ER function both negatively and positively via direct protein-protein interaction and ubiquitination (Ohtake et al., 2003, 2007). Specifically, ER $\alpha$ was recruited with AHR to the CYP1A promoter in vitro following TCDD treatment (Matthews et al., 2005). If ER $\alpha$ is a necessary cofactor for TCDDmediated AHR activity, inhibition or deletion of ER $\alpha$ should abrogate the response to AHR activation. We found, however, that pharmacologic or genetic inhibition of any of the zebrafish 
estrogen receptors failed to prevent Ahr2-dependent TCDD toxicity in embryos. Our results demonstrate that ERs are not constitutive partners of AHR and supports the hypothesis that AHR cofactor recruitment is context dependent.

\section{SUPPLEMENTARY DATA}

Supplementary data are available at Toxicological Sciences online.

\section{ACKNOWLEDGMENTS}

We thank Jeffery King and Marijke Schrock for technical support. We thank Dr Susan Farmer and Angela Mannone and the fish caretakers for help with zebrafish husbandry. We thank Dr Matthew P. Harris for advice on micro-CT analysis.

\section{FUNDING}

This work was supported by National Institute of Environmental Health Sciences (R01ES026337 to D.A.G.) and National Institute of General Medical Sciences (T32GM008361 to J.P.S.).

\section{DECLARATION OF CONFLICTING INTERESTS}

The authors declared no potential conflicts of interest with respect to the research, authorship, and/or publication of this article.

\section{REFERENCES}

Ablain, J., Durand, E. M., Yang, S., Zhou, Y., and Zon, L. I. (2015). A CRISPR/Cas9 vector system for tissue-specific gene disruption in zebrafish. Dev. Cell 32, 756-764.

Andreasen, E. A., Hahn, M. E., Heideman, W., Peterson, R. E., and Tanguay, R. L. (2002). The zebrafish (Danio rerio) aryl hydrocarbon receptor type 1 is a novel vertebrate receptor. Mol. Pharmacol. 62, 234-249.

Andreasen, E. A., Spitsbergen, J. M., Tanguay, R. L., Stegeman, J. J., Heideman, W., and Peterson, R. E. (2002). Tissue-specific expression of AHR2, ARNT2, and CYP1A in zebrafish embryos and larvae: Effects of developmental stage and 2,3,7,8-tetrachlorodibenzo-p-dioxin exposure. Toxicol. Sci. 68, 403-419.

Balik-Meisner, M., Truong, L., Scholl, E. H., Tanguay, R. L., and Reif, D. M. (2018). Population genetic diversity in zebrafish lines. Mamm. Genome 29, 90-100.

Beischlag, T. V., and Perdew, G. H. (2005). ER $\alpha$-AHR-ARNT protein-protein interactions mediate estradiol-dependent transrepression of dioxin-inducible gene transcription. J. Biol. Chem. 280, 21607-21611.

Belair, C. D., Peterson, R. E., and Heideman, W. (2001). Disruption of erythropoiesis by dioxin in the zebrafish. Dev. Dyn. 222, 581-594.

Blum, M., De Robertis, E. M., Wallingford, J. B., and Niehrs, C. (2015). Morpholinos: Antisense and sensibility. Dev. Cell 35, 145-149.

Bunger, M. K., Glover, E., Moran, S. M., Walisser, J. A., Lahvis, G. P., Hsu, E. L., and Bradfield, C. A. (2008). Abnormal liver development and resistance to 2,3,7,8-tetrachlorodibenzo-p-dioxin toxicity in mice carrying a mutation in the DNA-binding domain of the aryl hydrocarbon receptor. Toxicol. Sci. 106, 83-92.

Bunger, M. K., Moran, S. M., Glover, E., Thomae, T. L., Lahvis, G. P., Lin, B. C., and Bradfield, C. A. (2003). Resistance to 2,3,7,8tetrachlorodibenzo-p-dioxin toxicity and abnormal liver development in mice carrying a mutation in the nuclear localization sequence of the aryl hydrocarbon receptor. J. Biol. Chem. 278, 17767-17774.

Burbach, K. M., Poland, A., and Bradfield, C. A. (1992). Cloning of the Ah-receptor cDNA reveals a distinctive ligand-activated transcription factor. Proc. Natl. Acad. Sci. U.S.A. 89, 8185-8189.

Cuthill, S., Hapgood, J., Denis, M., Wilhelmsson, A., Mason, G., Takayuki, N., Widmark, E., Poellinger, L., and Gustafsson, J.$\AA$. (1989). Ligand-dependent interaction of the dioxin receptor with target DNA. J. Steroid Biochem. 34, 375-377.

Denison, M. S., Fisher, J. M., and Whitlock, J. P. (1988a). The DNA recognition site for the dioxin-Ah receptor complex. Nucleotide sequence and functional analysis. J. Biol. Chem. 263, 17221-17224.

Denison, M. S., Fisher, J. M., and Whitlock, J. P. (1988b). Inducible, receptor-dependent protein-DNA interactions at a dioxinresponsive transcriptional enhancer. Proc. Natl. Acad. Sci. U.S.A. 85, 2528-2532.

Fernandez-Salguero, P. M., Hilbert, D. M., Rudikoff, S., Ward, J. M., and Gonzalez, F. J. (1996). Aryl-hydrocarbon receptordeficient mice are resistant to 2,3,7,8-tetrachlorodibenzo-pdioxin-induced toxicity. Toxicol. Appl. Pharmacol. 140, 173-179.

Fernandez-Salguero, P., Pineau, T., Hilbert, D., McPhail, T., Lee, S., Kimura, S., Nebert, D., Rudikoff, S., Ward, J., and Gonzalez, F. (1995). Immune system impairment and hepatic fibrosis in mice lacking the dioxin-ebinding Ah receptor. Science 268, 722-726.

Fisher, S., Jagadeeswaran, P., and Halpern, M. E. (2003). Radiographic analysis of zebrafish skeletal defects. Dev. Biol. 264, 64-76.

Flesch-Janys, D., Berger, J., Gum, P., Manz, A., Nagel, S., Waltsgott, H., and Dwyer, J. H. (1995). Exposure to polychlorinated dioxins and furans (PCDD/F) and mortality in a cohort of workers from a herbicide-producing plant in Hamburg, Federal Republic of Germany. Am. J. Epidemiol. 142, 1165-1175.

Fujisawa-Sehara, A., Sogawa, K., Yamane, M., and FujiiKuriyama, Y. (1987). Characterization of xenobiotic responsive elements upstream from the drug-metabolizing cytochrome P-450c gene: A similarity to glucocorticoid regulatory elements. Nucleic Acids Res. 15, 4179-4191.

Fujisawa-Sehara, A., Yamane, M., and Fujii-Kuriyama, Y. (1988). A DNA-binding factor specific for xenobiotic responsive elements of P-450c gene exists as a cryptic form in cytoplasm: Its possible translocation to nucleus. Proc. Natl. Acad. Sci. U.S.A. 85, 5859-5863.

Garcia, G. R., Bugel, S. M., Truong, L., Spagnoli, S., and Tanguay, R. L. (2018). AHR2 required for normal behavioral responses and proper development of the skeletal and reproductive systems in zebrafish. PLoS One 13, e0193484.

Garner, L. V., Brown, D. R., and Di Giulio, R. T. (2013). Knockdown of AHR1A but not AHR1B exacerbates PAH and PCB-126 toxicity in zebrafish (Danio rerio) embryos. Aquat. Toxicol. 142-143, 336-346.

Gerety, S. S., and Wilkinson, D. G. (2011). Morpholino artifacts provide pitfalls and reveal a novel role for pro-apoptotic genes in hindbrain boundary development. Dev. Biol. 350, 279-289. 
Gonzalez, F. J., and Fernandez-Salguero, P. (1998). The aryl hydrocarbon receptor: Studies using the AHR-null mice. Drug Metab. Dispos. 26, 1194-1198.

Goodale, B. C., La Du, J. K., Bisson, W. H., Janszen, D. B., Waters, K. M., and Tanguay, R. L. (2012). AHR2 mutant reveals functional diversity of aryl hydrocarbon receptors in zebrafish. PLoS One 7, e29346.

Haffter, P., Odenthal, J, Mullins, M. C., Lin, S., Farrell, M. J., Vogelsang, E., Haas, F., Brand, M., van Eeden, F. J. M., FurutaniSeiki, M., et al. (1996). Mutations affecting pigmentation and shape of the adult zebrafish. Dev. Genes Evol. 206, 260-276.

Hahn, M. E., Karchner, S. I., Shapiro, M. A., and Perera, S. A. (1997). Molecular evolution of two vertebrate aryl hydrocarbon (dioxin) receptors (AHR1 and AHR2) and the PAS family. Proc. Natl. Acad. Sci. 94, 13743.

Hapgood, J., Cuthill, S., Denis, M., Poellinger, L., and Gustafsson, J. A. (1989). Specific protein-DNA interactions at a xenobioticresponsive element: Copurification of dioxin receptor and DNA-binding activity. Proc. Natl. Acad. Sci. U.S.A. 86, 60-64.

Harris, M. P., Rohner, N., Schwarz, H., Perathoner, S., Konstantinidis, P., and Nüsslein-Volhard, C. (2008). Zebrafish eda and edar mutants reveal conserved and ancestral roles of ectodysplasin signaling in vertebrates. PLoS Genet. 4, e1000206.

Henke, K., Daane, J. M., Hawkins, M. B., Dooley, C. M., BuschNentwich, E. M., Stemple, D. L., and Harris, M. P. (2017). Genetic screen for postembryonic development in the zebrafish (Danio rerio): Dominant mutations affecting adult form. Genetics 207, 609.

Henry, T. R., Spitsbergen, J. M., Hornung, M. W., Abnet, C. C., and Peterson, R. E. (1997). Early life stage toxicity of 2,3,7,8-tetrachlorodibenzo-p-dioxin in zebrafish (Danio rerio). Toxicol. Appl. Pharmacol. 142, 56-68.

Incardona, J. P., Day, H. L., Collier, T. K., and Scholz, N. L. (2006). Developmental toxicity of 4-ring polycyclic aromatic hydrocarbons in zebrafish is differentially dependent on AH receptor isoforms and hepatic cytochrome P4501A metabolism. Toxicol. Appl. Pharmacol. 217, 308-321.

Kais, B., Schiwy, S., Hollert, H., Keiter, S. H., and Braunbeck, T. (2017). In vivo EROD assays with the zebrafish (Danio rerio) as rapid screening tools for the detection of dioxin-like activity. Sci. Total Environ. 590-591, 269-280.

Karchner, S. I., Franks, D. G., and Hahn, M. E. (2005). AHR1B, a new functional aryl hydrocarbon receptor in zebrafish: Tandem arrangement of ahr1b and ahr2 genes. Biochem. J. 392, 153-161.

Kawanishi, M., Kondo, M., Shiizaki, K., Chu, W. L., Terasoma, Y., and Yagi, T. (2008). Construction of a reporter yeast strain to detect estrogen receptor signaling through aryl hydrocarbon receptor activation. Environ. Sci. Technol. 42, 6897-6902.

Kimmel, C. B., Ullmann, B., Walker, M., Miller, C. T., and Crump, J. G. (2003). Endothelin 1-mediated regulation of pharyngeal bone development in zebrafish. Development 130, 1339.

Kimmel, C. B., Walker, M. B., and Miller, C. T. (2007). Morphing the hyomandibular skeleton in development and evolution. J. Exp. Zool. B Mol. Dev. Evol. 308B, 609-624.

Kok, F. O., Shin, M., Ni, C., Gupta, A., Grosse, A. S., van Impel, A., Kirchmaier, B. C., Peterson-Maduro, J., Kourkoulis, G., and Male, I. (2014). Reverse genetic screening reveals poor correlation between morpholino-induced and mutant phenotypes in zebrafish. Dev. Cell; 32, 97-108.

Kumar, M. B., and Perdew, G. H. (1999). Nuclear receptor coactivator SRC-1 interacts with the Q-rich subdomain of the AhR and modulates its transactivation potential. Gene Expr. 8, 273-286.
Lawson, N. D., and Weinstein, B. M. (2002). In vivo imaging of embryonic vascular development using transgenic zebrafish. Dev. Biol. 248, 307-318.

Matthews, J., Wihlen, B., Thomsen, J., and Gustafsson, J. A. (2005). Aryl hydrocarbon receptor-mediated transcription: Ligand-dependent recruitment of estrogen receptor alpha to 2,3,7,8-tetrachlorodibenzo-p-dioxin-responsive promoters. Mol. Cell. Biol. 25, 5317-5328.

Nacci, D., Coiro, L., Kuhn, A., Champlin, D., Munns, W., Jr, Specker, J., and Cooper, K. (1998). Nondestructive indicator of ethoxyresorufin-O-deethylase activity in embryonic fish. Environ. Toxicol. Chem. 17, 2481-2486.

Nguyen, T. A., Hoivik, D., Lee, J. E., and Safe, S. (1999). Interactions of nuclear receptor coactivator/corepressor proteins with the aryl hydrocarbon receptor complex. Arch. Biochem. Biophys. 367, 250-257.

O’Donnell, E. F., Saili, K. S., Koch, D. C., Kopparapu, P. R., Farrer, D., Bisson, W. H., Mathew, L. K., Sengupta, S., Kerkvliet, N. I., and Tanguay, R. L. (2010). The anti-inflammatory drug leflunomide is an agonist of the aryl hydrocarbon receptor. PLoS One 5, e13128.

Ohtake, F., Baba, A., Takada, I., Okada, M., Iwasaki, K., Miki, H., Takahashi, S., Kouzmenko, A., Nohara, K., Chiba, T., et al. (2007). Dioxin receptor is a ligand-dependent E3 ubiquitin ligase. Nature 446, 562-566.

Ohtake, F., Takeyama, K., Matsumoto, T., Kitagawa, H., Yamamoto, Y., Nohara, K., Tohyama, C., Krust, A., Mimura, J., Chambon, P., et al. (2003). Modulation of oestrogen receptor signalling by association with the activated dioxin receptor. Nature 423, 545-550.

Otte, J. C., Schmidt, A. D., Hollert, H., and Braunbeck, T. (2010). Spatio-temporal development of CYP1 activity in early life-stages of zebrafish (Danio rerio). Aquat. Toxicol. 100, 38-50.

Parant, J. M., George, S. A., Pryor, R., Wittwer, C. T., and Yost, H. J. (2009). A rapid and efficient method of genotyping zebrafish mutants. Dev. Dyn. 238, 3168-3174.

Parichy, D. M., Elizondo, M. R., Mills, M. G., Gordon, T. N., and Engeszer, R. E. (2009). Normal table of postembryonic zebrafish development: Staging by externally visible anatomy of the living fish. Dev. Dyn. 238, 2975-3015.

Parsons, K. J., Andreeva, V.J., Cooper, W., Yelick, P.C., and Craig Albertson, R. (2011). Chapter 11-Morphogenesis of the zebrafish jaw: Development beyond the embryo. In Methods in Cell Biology (H. W. Detrich, M. Westerfield, and L. I. Zon, Eds.), Vol. 101, pp. 225-248. Academic Press, Cambridge, Massachusetts.

Prasch, A. L., Teraoka, H., Carney, S. A., Dong, W., Hiraga, T., Stegeman, J. J., Heideman, W., and Peterson, R. E. (2003). Aryl hydrocarbon receptor 2 mediates 2,3,7,8-tetrachlorodibenzop-dioxin developmental toxicity in zebrafish. Toxicol. Sci. 76, 138-150.

Quintana, F. J., Basso, A. S., Iglesias, A. H., Korn, T., Farez, M. F., Bettelli, E., Caccamo, M., Oukka, M., and Weiner, H. L. (2008). Control of $\mathrm{T}(\mathrm{reg})$ and $\mathrm{T}(\mathrm{H}) 17$ cell differentiation by the aryl hydrocarbon receptor. Nature 453, 65-71.

Reyes, H., Reisz-Porszasz, S., and Hankinson, O. (1992). Identification of the Ah receptor nuclear translocator protein (Arnt) as a component of the DNA binding form of the Ah receptor. Science 256, 1193-1195.

Romano, S. N., Edwards, H. E., Souder, J. P., Ryan, K. J., Cui, X., and Gorelick, D. A. (2017). G protein-coupled estrogen receptor regulates embryonic heart rate in zebrafish. PLoS Genet. 13, e1007069. 
Rüegg, J., Swedenborg, E., Wahlström, D., Escande, A., Balaguer, P., Pettersson, K., and Pongratz, I. (2008). The transcription factor aryl hydrocarbon receptor nuclear translocator functions as an estrogen receptor $\beta$-selective coactivator, and its recruitment to alternative pathways mediates antiestrogenic effects of dioxin. Mol. Endocrinol. 22, 304-316.

Schneider, C. A., Rasband, W. S., and Eliceiri, K. W. (2012). NIH image to ImageJ: 25 years of image analysis. Nat. Methods 9, 671-675.

Schulte-Merker, S., and Stainier, D. Y. (2014). Out with the old, in with the new: Reassessing morpholino knockdowns in light of genome editing technology. Development 141, 3103-3104.

Singh, K. P., Garrett, R. W., Casado, F. L., and Gasiewicz, T. A. (2011). Aryl hydrocarbon receptor-null allele mice have hematopoietic stem/progenitor cells with abnormal characteristics and functions. Stem Cells Dev. 20, 769-784.

Sire, J.-Y., and Huysseune, A. N. N. (2003). Formation of dermal skeletal and dental tissues in fish: A comparative and evolutionary approach. Biol. Rev. 78, 219-249.

Stainier, D. Y. R., Kontarakis, Z., and Rossi, A. (2015). Making sense of anti-sense data. Dev. Cell 32, 7-8.

Sugden, W. W., Leonardo-Mendonça, R. C., Acuña-Castroviejo, D., and Siekmann, A. F. (2017). Genetic dissection of endothelial transcriptional activity of zebrafish aryl hydrocarbon receptors (AHRs). PLoS One 12, e0183433.

Swedenborg, E., Ruegg, J., Hillenweck, A., Rehnmark, S., Faulds, M. H., Zalko, D., Pongratz, I., and Pettersson, K. (2007). 3Methylcholanthrene displays dual effects on estrogen receptor (ER) alpha and ER beta signaling in a cell-type specific fashion. Mol. Pharmacol. 73, 575-586.

Tanguay, R. L., Abnet, C. C., Heideman, W., and Peterson, R. E. (1999). Cloning and characterization of the zebrafish (Danio rerio) aryl hydrocarbon receptor. Biochim. Biophys. Acta 1444, 35-48.
Tanguay, R. L., Andreasen, E., Heideman, W., and Peterson, R. E. (2000). Identification and expression of alternatively spliced aryl hydrocarbon nuclear translocator 2 (ARNT2) cDNAs from zebrafish with distinct functions. Biochim. Biophys. Acta 1494, 117-128.

Teraoka, H., Dong, W., Ogawa, S., Tsukiyama, S., Okuhara, Y., Niiyama, M., Ueno, N., Peterson, R. E., and Hiraga, T. (2002). 2,3,7,8-Tetrachlorodibenzo-p-dioxin toxicity in the zebrafish embryo: Altered regional blood flow and impaired lower jaw development. Toxicol. Sci. 65, 192-199.

Thackaberry, E. A., Bedrick, E. J., Goens, M. B., Danielson, L. Lund, A. K., Gabaldon, D., Smith, S. M., and Walker, M. K. (2003). Insulin regulation in AhR-null mice: Embryonic cardiac enlargement, neonatal macrosomia, and altered insulin regulation and response in pregnant and aging AhR-null females. Toxicol. Sci. 76, 407-417.

Traver, D., Paw, B. H., Poss, K. D., Penberthy, W. T., Lin, S., and Zon, L. I. (2003). Transplantation and in vivo imaging of multilineage engraftment in zebrafish bloodless mutants. Nat. Immunol. 4, 1238-1246. 10.1038/ni1007).

van Eeden, F. J., Granato, M., Schach, U., Brand, M., FurutaniSeiki, M., Haffter, P., Hammerschmidt, M., Heisenberg, C. P., Jiang, Y. J., Kane, D. A., et al. (1996). Genetic analysis of fin formation in the zebrafish, Danio rerio. Development 123, 255.

Verbueken, E., Bars, C., Ball, S. J., Periz-Stanacev, J., Marei, F. W., Tochwin, A., Gabriëls, J. I., Michiels, D. E., Stinckens, E., Vergauwen, L., et al. (2018). From mRNA expression of drug disposition genes to in vivo assessment of CYP-mediated biotransformation during zebrafish embryonic and larval development. Int. J. Mol. Sci. 19, 3976.

Westerfield, M. (2000). The Zebrafish Book. A Guide for the Laboratory Use of Zebrafish (Danio rerio), 4th ed. University of Oregon Press, Eugene, OR. 